Louisiana State University

LSU Digital Commons

Faculty Publications

Department of Biological Sciences

$1-1-2001$

\title{
Evolutionary implications of divergent clines in an avian (Manacus: Aves) hybrid zone
}

\author{
Robb T. Brumfield \\ Smithsonian National Museum of Natural History \\ Robert W. Jernigan \\ American University \\ David B. McDonald \\ University of Wyoming \\ Michael J. Braun \\ Smithsonian National Museum of Natural History
}

Follow this and additional works at: https://digitalcommons.Isu.edu/biosci_pubs

\section{Recommended Citation}

Brumfield, R., Jernigan, R., McDonald, D., \& Braun, M. (2001). Evolutionary implications of divergent clines in an avian (Manacus: Aves) hybrid zone. Evolution, 55(10), 2070-2087. https://doi.org/10.1111/ j.0014-3820.2001.tb01322.x

This Article is brought to you for free and open access by the Department of Biological Sciences at LSU Digital Commons. It has been accepted for inclusion in Faculty Publications by an authorized administrator of LSU Digital Commons. For more information, please contact ir@lsu.edu. 


\title{
EVOLUTIONARY IMPLICATIONS OF DIVERGENT CLINES IN AN AVIAN (MANACUS: AVES) HYBRID ZONE
}

\author{
Robb T. Brumfield, ${ }^{1,2,3}$ Robert W. Jernigan, ${ }^{4,5}$ David B. McDonald, ${ }^{6,7}$ And Michael J. Braun ${ }^{1,2,8}$ \\ ${ }^{1}$ Laboratory of Molecular Systematics, National Museum of Natural History, Smithsonian Institution MRC 534, \\ Washington, D.C. 20560 \\ ${ }^{2}$ Department of Biology, University of Maryland, College Park, Maryland 20742 \\ ${ }^{4}$ Department of Mathematics and Statistics, American University, Washington, D.C. 20016 \\ ${ }^{5}$ E-mail: jernigan@american.edu \\ ${ }^{6}$ Department of Zoology and Physiology, University of Wyoming, Laramie, Wyoming 82071 \\ ${ }^{7}$ E-mail: dbmcd@uwyo.edu \\ ${ }^{8}$ E-mail:braun@lms.si.edu
}

\begin{abstract}
A previous study of the hybrid zone in western Panama between white-collared (Manacus candei) and golden-collared manakins ( $M$. vitellinus) documented the unidirectional introgression of vitellinus male secondary sexual traits across the zone. Here, we examine the hybrid zone in greater genetic and morphological detail. Statistical comparisons of clines are performed using maximum-likelihood and nonparametric bootstrap methods. Our results demonstrate that an array of six molecular and two morphometric markers agree in cline position and width. Clines for male collar and belly color are similar in width to the first eight clines, but are shifted in position by at least five cline widths. The result is that birds in intervening populations are genetically and morphometrically very like parental candei, but males have the plumage color of parental vitellinus. Neither neutral diffusion nor nonlinearity of color scales appear to be viable explanations for the large cline shifts. Genetic dominance of vitellinus plumage traits is another potential explanation that will require breeding experiments to test. Sexual selection remains a plausible explanation for the observed introgression of vitellinus color traits in these highly dimorphic, polygynous, lek-mating birds. Two other clines, including a nondiagnostic isozyme locus, are similar in position to the main cluster of clines, but are broader in width. Thus, introgression at some loci is greater than that detected with diagnostic markers. Assuming that narrow clines are maintained by selection, variation in cline width indicates that selection is not uniform throughout the genome and that diagnostic markers are under more intense selective pressure. The traditional focus on diagnostic markers in studies of hybrid zones may therefore lead to underestimates of average introgression. This effect may be more pronounced in organisms with low levels of genetic divergence between hybridizing taxa.
\end{abstract}

Key words.-Cline, hybrid zone, introgression, Manacus, manakin, sexual selection, speciation.

Received October 20, 2000. Accepted June 18, 2001.

Within a reproductively isolated group of organisms, the majority of new alleles upon which natural selection can act arise from mutation or recombination. Hybridization affords another source of new alleles, one that is available only to organisms with incomplete reproductive isolation from other divergent taxa (Anderson 1949; Stebbins 1959; Arnold 1997). Divergent eubacteria that have transferred plasmids harboring antibiotic-resistance genes are examples of the important role that hybridization can play in evolution (Spratt et al. 1989), as are studies documenting the increased fitness of introgressed populations that have successfully exploited new habitats (Lewontin and Birch 1966) or habitats unsuitable to either parental form (Anderson 1949; Stebbins 1959; Grant 1981; Arnold 1992).

Anderson and Hubricht (1938) coined the term "introgressive hybridization" to describe the genetic interconnectedness of hybridizing populations and proposed that hybrids provide a means for advantageous genes to move between differentiated taxa. Anderson (1949) emphasized that the evolutionary significance of introgression may be concealed by difficulty in detecting it. Without a detailed understanding of the genetic architecture of the hybridizing forms, introgressing genes that have little or no effect on

\footnotetext{
${ }^{3}$ Present address: Department of Zoology, Box 351800, University of Washington, Seattle, Washington 98195; E-mail: brumfld@ u.washington.edu.
}

morphology will be difficult to detect (Barton 2001). In extreme cases, hybridizing taxa whose morphological differences are maintained by one or a few genes (e.g., butterflies, Sheppard et al. 1985) could be exchanging genes freely across the rest of their genomes, yet maintaining sharp boundaries between morphotypes (e.g., oaks, DumolinLapégue et al. 1999).

Hybrid zones, where genetically divergent forms meet and hybridize (Harrison 1990), are natural arenas in which to examine the evolutionary potential of introgression (Rieseberg et al. 1999). Cline theory provides a conceptual framework to understand both the maintenance of hybrid zones and the relevant evolutionary parameters involved in the movement of traits across them (Haldane 1948; Slatkin 1973; May et al. 1975; Endler 1977; Barton 1979; Szymura and Barton 1986). Most hybrid zones are thought to be maintained as tension zones by a balance between the dispersal of parentals into the zone and selection (Haldane 1948; Barton 2001). Both endogenous (e.g., intrinsic) and exogenous (e.g., environmental) selection can result in barriers to the movement of genes across a hybrid zone (Hewitt 1988). Endogenous selection may be due to the breakdown of coadapted gene complexes (Grant and Grant 1994), whereas exogenous selection may result from a wide variety of environmental gradients. To cross such a barrier, an allele must recombine into a favorable, or at least viable, genetic background (Anderson 1949; Stebbins 1959; Barton 1979). If selection 


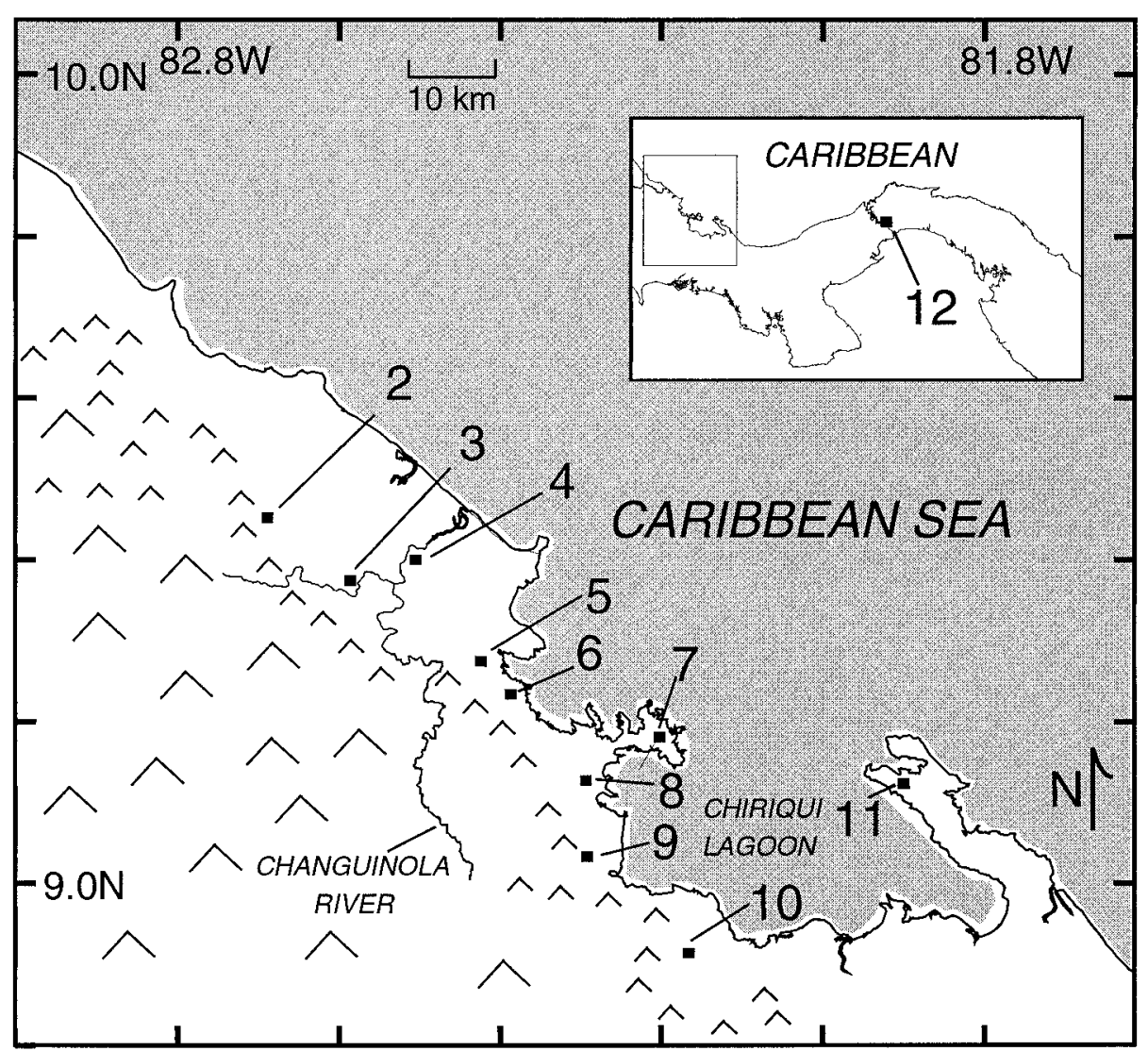

FIG. 1. Map of western Bocas del Toro, Panama and extreme eastern Costa Rica indicating populations 2-12 sampled across the candeivitellinus hybrid zone. Detailed locality information is in the Appendix. Population 1 lies off this map, $138.25 \mathrm{~km}$ northwest of population 2. The northeastern extent of the mountains represents 500-m elevation contour.

against hybrids is strong or if genes that contribute to reduced hybrid fitness are distributed throughout the genome (Kim and Rieseberg 1999), such gene combinations may be rare (Key 1968) or nonexistent for some loci. In addition, favorable combinations would initially arise at low frequencies and could be lost by drift (Piálek and Barton 1997). However, once a positively selected trait does cross a hybrid zone and begins to increase in frequency, it should sweep rapidly through the new population, leaving no easily detectable signature (Hewitt 1988). Thus, it is likely to be observed only rarely in nature (Anderson 1949; Barton 2001).

An interesting case of apparent introgression was documented by Parsons et al. (1993) in their study of a hybrid zone between the closely related white-collared (Manacus candei) and golden-collared manakins (M. vitellinus). These sexually dichromatic, lek-mating birds are divergent in a number of morphological characters, but their most striking differences lie in the color of the definitive male collar plumage (golden yellow in vitellinus; white in candei), and in the color of their belly plumage (drab green in vitellinus; lemon yellow in candei). Parsons et al. (1993) found that clines in several male plumage traits were shifted approximately 40 $\mathrm{km}$ northwest of the clines for three molecular genetic markers and two morphometric markers. They interpreted the shifted clines as evidence that the plumage traits of vitellinus were introgressing unidirectionally across the hybrid zone.
The facts that the introgressing male plumage characters are secondary sexual traits and that mating success is highly skewed in these lek-mating birds (Lill 1974) led Parsons et al. (1993) to suggest that introgression might be due to positive sexual selection for vitellinus plumage traits. Other than the shifted plumage clines, the hybrid zone uniting candei and vitellinus appeared typical of most described hybrid zones (Moore 1977; Barton and Hewitt 1985, 1989), with numerous character transition clines of the same approximate width and position.

Butlin and Neems (1994) suggested that the Manacus plumage clines might not be shifted in position at all, but might simply be much wider than clines for molecular and morphometric characters. They also suggested that if any of the clines were indeed shifted, the shift might be due to genetic dominance of vitellinus traits or to the nonlinear color index used, with the underlying allele frequency clines actually coincident in position with the other clines. Butlin and Neems preferred an interpretation of the data wherein male plumage is irrelevant to mating success and the plumage clines have become broader (or perhaps shifted slightly) due to neutral diffusion. Parsons et al. (1994) rebutted these arguments, while acknowledging that further evidence was highly desirable.

To address these issues, we reexamined the genetic and morphological structure of the hybrid zone in greater detail. 
TABLE 1. Summary of morphological measurements that differ significantly across the hybrid zone transect. Mean, standard deviation (SD), and number of individuals measured $(N)$ are presented for each population. Population 1 is the reference sample for candei and population 12 is the reference sample for vitellinus. See Figure 1 and Appendix for detailed locality information.

\begin{tabular}{|c|c|c|c|c|c|c|c|c|c|c|c|c|c|}
\hline \multirow[b]{2}{*}{ Population } & \multirow{2}{*}{$\begin{array}{l}\text { Distance } \\
(\mathrm{km})\end{array}$} & \multicolumn{3}{|c|}{ Mass (g) } & \multicolumn{3}{|c|}{ Wing length $(\mathrm{mm})$} & \multicolumn{3}{|c|}{ Culmen length (mm) } & \multicolumn{3}{|c|}{ Bill depth (mm) } \\
\hline & & Mean & SD & $N$ & Mean & SD & $N$ & Mean & $\mathrm{SD}$ & $N$ & Mean & SD & $N$ \\
\hline 1 & 0 & 18.2 & 0.88 & 21 & 53.3 & 1.04 & 22 & 9.6 & 0.49 & 20 & 3.6 & 0.22 & 22 \\
\hline 2 & 138.25 & 19.4 & 0.42 & 5 & 52.6 & 0.79 & 4 & 9.5 & 0.45 & 5 & 3.4 & 0.13 & 5 \\
\hline 4 & 159.5 & 19.8 & 0.78 & 21 & 52.9 & 0.90 & 9 & 9.6 & 0.31 & 15 & 3.4 & 0.17 & 15 \\
\hline 5 & 182.25 & 19.6 & 1.21 & 18 & 53.6 & 1.00 & 15 & 9.9 & 0.35 & 17 & 3.6 & 0.17 & 12 \\
\hline 6 & 188.25 & 20.0 & 1.20 & 12 & 53.5 & 0.38 & 5 & 9.5 & 0.60 & 11 & 3.4 & 0.28 & 11 \\
\hline 9 & 210.0 & 18.9 & 0.74 & 13 & 52.2 & 0.86 & 19 & 10.0 & 0.49 & 9 & 3.2 & 0.13 & 9 \\
\hline 10 & 230.75 & 20.0 & 0.76 & 16 & 51.1 & 0.63 & 10 & 10.0 & 0.64 & 7 & 3.3 & 0.21 & 7 \\
\hline 11 & 319.5 & 19.4 & 0.66 & 4 & 51.2 & 0.80 & 5 & 10.2 & 0.35 & 2 & 3.4 & 0.35 & 2 \\
\hline 12 & 569.5 & 17.7 & 1.15 & 3 & 51.6 & 0.81 & 21 & 10.1 & 0.46 & 20 & 4.0 & 0.20 & 19 \\
\hline
\end{tabular}

Here, we present analyses based on an expanded data set of seven molecular markers and 12 morphological characters. We sampled new populations and increased the sample size of others to measure the position and widths of the character clines more accurately, and we refined the measurement of color traits using reflectance spectrophotometry. We surveyed wild populations for the homozygous recessive whitecollared birds expected under a hypothesis of genetic dominance of vitellinus alleles. As a statistical framework for comparing the structure of individual character clines, we employ the maximum-likelihood methods of Barton and Baird (1999) to estimate confidence intervals for the molecular cline parameters and use the nonparametric bootstrap to compare molecular and morphological clines.

\section{Materials And Methods \\ Population Samples}

From 1989 to 1994, we collected 173 specimens along a transect (Fig. 1, populations 2-11) through a narrow coastal strip of humid, lowland, second-growth forest and abandoned banana and cacao plantations in western Bocas del Toro, Panama. Because Parsons et al. (1993) focused their sampling on the area of plumage transition at the Changuinola River, they lacked samples from the actual hybrid zone center. In 1994, we collected individuals from populations 8 and 9 (Fig. 1) to sample intensively in the center of the steep genetic and morphometric character transitions identified by Parsons et al. (1993). Thus, populations 10-12 of this paper correspond to populations 8-10 of Parsons et al. (1993). Specimens were deposited at the U.S. National Museum of Natural History (USNM) and the Universidad de Panama. Skeletal muscle, liver, and heart tissue samples were stored in liquid nitrogen.

To serve as reference parental samples for the genetic markers, we collected 20 individuals of vitellinus approximately $250 \mathrm{~km}$ east of the hybrid zone (population 12), and borrowed from the Louisiana State University Museum of Natural Science (LSUMNS) frozen tissues from six individuals of candei collected $140 \mathrm{~km}$ west of the hybrid zone (population 1). We used 16 blood samples collected from birds that were banded and released to augment the popu- lation 2 sample, which was composed of only three individuals in Parsons et al. (1993). Thus, for the genetic markers, we assayed a total of 215 specimens, consisting of definitively plumaged males ( $\geq 2$ years old), first-year males, and females.

For the morphological markers, we measured a total of 122 definitively plumaged male specimens from the transect (Fig. 1, populations 2-11). The parental sample of candei was composed of 22 specimens collected in Costa Rica (19 specimens collected between the years 1893 and 1928 and three specimens collected in 1990). A parental sample of vitellinus was composed of 22 specimens collected in the Canal Zone between the years 1911 and 1994. The overall sample size for the morphological characters $(N=166)$ was less than for the genetic characters and more variable among populations, primarily because some specimens (e.g., first-year males, females, skeletons) could not be assayed for the morphological characters. Catalog numbers for all specimens appear in the Appendix.

\section{Morphometric Characters}

The mass of each specimen was measured in the field prior to specimen preparation, or, for historical specimens, was noted from the museum tag. On definitively plumaged males, R. T. Brumfield measured seven morphometric characters with dial calipers (to the nearest $0.1 \mathrm{~mm}$ ): wing length (chord of unflattened wing from bend of wing to longest primary); culmen length (exposed culmen); nare length (from anterior edge of nare to tip of bill); bill depth (at its base); bill width (at its base); tail length (measured from point of insertion of central rectrices to tip of longest rectrix); and tarsus length (from the joint of tarsometatarsus and tibiotarsus to the lateral edge of last undivided scute). Two plumage characters were measured with a ruler (to the nearest $0.5 \mathrm{~mm}$ ): epaulet width (from bend of folded wing to posterior edge of white or yellow epaulet feathers) and beard length (measured from insertion to tip of longest feather). Throughout the paper, we use the terms "'morphometric' characters to refer to the foregoing 10 characters and "plumage color" characters in reference to male collar color and belly color measurements 
TABLE 1. Extended.

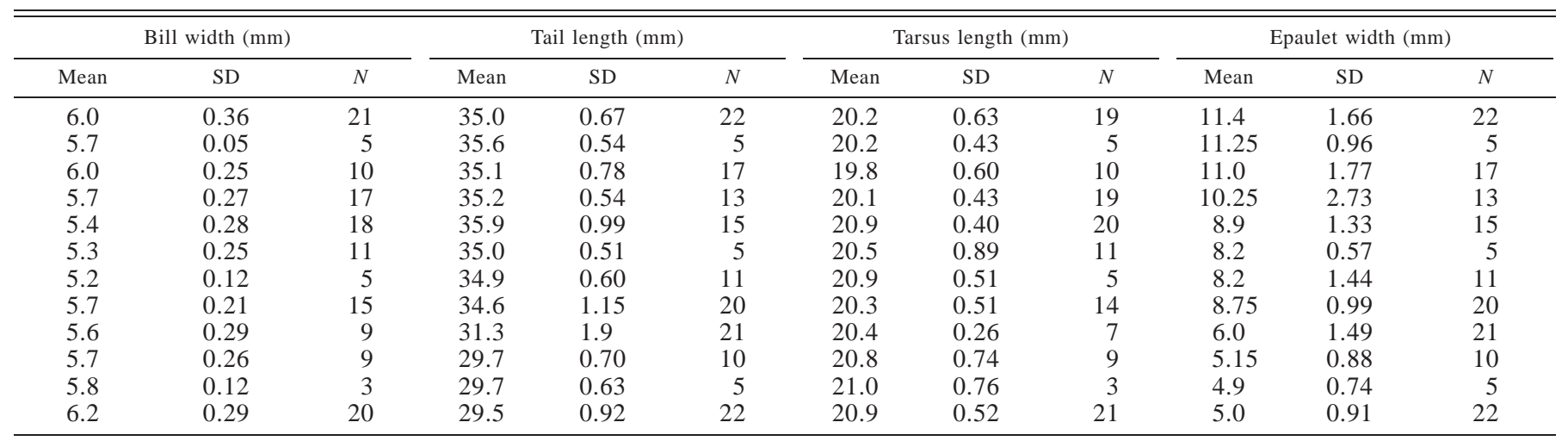

(described below). "Morphological"' data refers to all of the above characters.

We performed statistical and multivariate analyses of the morphological data (Table 1) using the JMP software package (SAS Institute 2000). Parental reference samples had significantly different means for all of the morphometric characters except nare length (Brumfield 1999). Variation in some of the morphometric characters, such as mass, wing length, tail length, and tarsus length, likely reflect correlated differences in overall size. Variation in these characters was summarized by means of a principal components analysis (PCA) of the correlation matrix. It seems reasonable to assume that variation in plumage characters, such as beard length, epaulet width, collar color, and belly color, do not reflect variation in overall size, and so these characters were treated independently in all subsequent analyses. Specimens missing data for more than two characters $(N=24)$ were excluded from the PCA. We estimated missing values for the remaining specimens using multiple regression.

The first principal components axis (PC1) explained $37 \%$ of the variation, with roughly equivalent loadings (0.39-0.50) among mass, wing length, tail length, and tarsus length. Loadings on $\mathrm{PC} 2$, which explained $24 \%$ of the variation, were highest (0.35-0.65) among the three bill characters (culmen length, bill width, bill depth). Bill morphology, described by the second component, did not exhibit obvious clinal variation, and was not analyzed further. Variation at PC3 was also not clinal. We repeated the PCA excluding the bill characters, reducing the number of excluded individuals from 24 to 19 (excluded individuals listed in the Appendix). PC1 exhibited strong clinal variation and explained $59 \%$ of the variation, with similar loadings among all four characters (mass, wing length, tarsus length, and tail length). Variation at PC2 and PC3 was not clinal. Loadings on PC2, which explained $20 \%$ of the variation, were similar in magnitude among the four characters.

\section{Plumage Color Measurements}

We measured male collar and belly color using an Ultrascan (Hunter Labs, Inc., Reston, VA) integrating sphere reflectance spectrophotometer. Percentage reflectance at each wavelength was measured relative to a pure white reflecting surface (100\% reflectance). The average of three independent measurements of the reflectance spectrum was taken for each specimen. We repositioned the specimen at the sample aperture before each replicate measurement. Collar and belly color measurements were taken near the center of the throat and belly, respectively, of each specimen. Thus, these represent more rigorous quantification of the semi-quantitative variables "throat color" and "underparts color"' of Parsons et al. (1993).

Several methods of summarizing color variation across the hybrid zone were considered (Endler 1990). A PCA of the entire reflectance spectrum was not adequate, because the most heavily weighted wavelengths were those with the highest variance instead of those that were most divergent between the parental forms. There are a number of color scales that summarize reflectance spectra in relation to human perception (Hunter 1975). Although they describe the color variation quantitatively, these scales do not have a biologically interpretable unit of measurement. For the full analysis, we opted to use the raw percent reflectance at $490 \mathrm{~nm}$ and 665 $\mathrm{nm}$ to represent collar color and belly color, respectively (Table 1). These wavelengths had the greatest differences in means between the two parental samples in otherwise rather simple spectra (Fig. 2). Other divergent wavelengths were examined, and all gave similar results. We also performed a discriminant function analysis, and this too gave similar results.

\section{Molecular Genetic Data}

Protein electrophoresis was performed on Titan III cellulose acetate plates (Helena Laboratories, Inc., Beaumont, TX). We identified the isozyme loci $A d a$ (E.C. 3.1.3.2), Ak2 (E.C. 2.7.4.3), Gsr (E.C. 1.6.4.2), and Pgm-2 (E.C. 2.7.5.1) as having significant genic differentiation between vitellinus and candei (Brumfield and Braun 2001). The presence of female heterozygotes indicates that all these loci are autosomal. $A k-2$ gels were run for $3 \mathrm{~h}$ at $125 \mathrm{~V}$ in a $\mathrm{pH} 7.5$ Triscitrate buffer (100 mM Tris, $36 \mathrm{mM}$ citric acid). To discriminate $A k-2$, the comigrating $A k-1$ locus was inactivated by incubating homogenates on ice with $1-2 \mathrm{mM} \mathrm{AgNO}_{3}$ for 10 min before electrophoresis (Harris and Hopkinson 1976). Running conditions for other loci and histochemical staining methods are presented in Brumfield (1999). Electromorphs were coded alphabetically in order of relative mobility from 
TABle 1. Extended.

\begin{tabular}{|c|c|c|c|c|c|c|c|c|c|c|c|c|c|}
\hline \multirow[b]{2}{*}{ Population } & \multirow{2}{*}{$\begin{array}{l}\text { Distance } \\
\quad(\mathrm{km})\end{array}$} & \multicolumn{3}{|c|}{ Beard length $(\mathrm{mm})$} & \multicolumn{3}{|c|}{$\begin{array}{c}\text { Collar color } \\
(\% \text { reflectance at } 490 \mathrm{~nm})\end{array}$} & \multicolumn{3}{|c|}{$\begin{array}{c}\text { Belly color } \\
(\% \text { reflectance at } 665 \mathrm{~nm})\end{array}$} & \multicolumn{3}{|c|}{ PC1 } \\
\hline & & Mean & SD & $N$ & Mean & $\mathrm{SD}$ & $N$ & Mean & $\mathrm{SD}$ & $N$ & Mean & SD & $N$ \\
\hline 1 & 0 & 12.4 & 0.90 & 22 & 57.2 & 5.14 & 22 & 67.7 & 5.79 & 22 & 0.75 & 0.16 & 20 \\
\hline 3 & 151.75 & 11.9 & 0.81 & 17 & 64.3 & 6.25 & 17 & 78.4 & 4.63 & 17 & 0.71 & 0.16 & 9 \\
\hline 4 & 159.5 & 12.2 & 0.83 & 13 & 11.4 & 3.59 & 13 & 44.7 & 11.76 & 13 & 0.62 & 0.12 & 9 \\
\hline 5 & 182.25 & 13.2 & 0.98 & 15 & 9.8 & 3.93 & 15 & 36.2 & 9.45 & 15 & 0.73 & 0.15 & 15 \\
\hline 8 & 201.25 & 12.2 & 1.22 & 20 & 6.3 & 2.16 & 20 & 26.9 & 4.27 & 20 & 0.69 & 0.11 & 20 \\
\hline 9 & 210.0 & 16.3 & 2.30 & 21 & $7.8^{1}$ & $12.77^{1}$ & $21^{1}$ & 25.8 & 5.04 & 21 & 0.47 & 0.15 & 19 \\
\hline 10 & 230.75 & 17.4 & 1.26 & 10 & 3.9 & 1.60 & 10 & 23.4 & 3.27 & 10 & 0.23 & 0.14 & 10 \\
\hline 11 & 319.5 & 18.8 & 1.92 & 5 & 3.4 & 1.23 & 5 & 23.2 & 3.49 & 5 & 0.34 & 0.12 & 5 \\
\hline 12 & 569.5 & 18.7 & 1.61 & 22 & 3.4 & 1.09 & 22 & 25.2 & 2.70 & 22 & 0.31 & 0.15 & 21 \\
\hline
\end{tabular}

${ }^{1}$ Measurements for collar color in population 9 excluding the aberrant white specimen (USNM 608981) are: mean $=5.0, \mathrm{SD}=2.54, N=20$.

the origin with the most anodally migrating allele as " $a$.", Among-gel comparisons of all alleles were made by rerunning selected individuals on cross-correlation gels. All four samples from population 6 and one sample (tissue catalog number B487) from population 7 were preserved in ethanol and could not be scored for the isozyme loci. In addition, the 16 blood samples used to augment the sample size of population 2 were not scored for the isozyme loci. Frozen specimens that did not include heart and liver tissues were not scored for $A k-2$ and $P g m-2$, respectively. Sample sizes and allele frequencies are given in Table 2.

DNA was isolated by proteinase $\mathrm{K}$ digestion and phenol/ chloroform extraction followed by ethanol precipitation. After digestion with restriction enzymes, DNA was transferred to nylon membranes (Southern 1975). Random priming (Feinberg and Vogelstein 1993) was used to label probes to high specific activity $\left(10^{8}-10^{9} \mathrm{dpm} / \mu \mathrm{g}\right)$ with $\alpha-{ }^{32} \mathrm{P}$ dATP. After probing and washing, wet membranes were wrapped in cellophane and exposed to Kodak (Rochester, NY) XRP film for $4-96 \mathrm{~h}$ at $-80^{\circ} \mathrm{C}$.

Parsons et al. (1993) identified three probes that detect diagnostic restriction fragment length variants in candei and vitellinus. $\lambda 5$ is a randomly cloned fragment of manakin DNA used to probe $B g l$ II digests. A $5.6-\mathrm{kb}$ band in vitellinus is cleaved into $3.7-\mathrm{kb}$ and $1.9-\mathrm{kb}$ bands in candei. The second probe, pSCN3, is a randomly cloned fragment of manakin DNA used to probe Ava II digests. A $5.5-\mathrm{kb}$ band in candei is cleaved into $4.8-\mathrm{kb}$ and $0.7-\mathrm{kb}$ bands in vitellinus. The presence of female heterozygotes indicates that both $\lambda 5$ and pSCN3 are nuclear, autosomal markers. A third probe is mitochondrial DNA (mtDNA) purified by cesium chloride gradient centrifugation (Dowling et al. 1996). MtDNA from vitellinus, an introgressed vitellinus-candei individual, and Carpodacus mexicanus (house finch) gave equivalent results when used as a probe of $B g l$ II $(\sim 28 \mathrm{~kb}$, presumably uncut band in vitellinus with $\sim 16-\mathrm{kb}$ band in candei), Ava I ( $\sim 28$ $\mathrm{kb}$ band in vitellinus with $\sim 23-\mathrm{kb}, \sim 3-\mathrm{kb}$, and $\sim 2-\mathrm{kb}$ bands in candei), and EcoR V ( 9.4-kb, $\sim 5-\mathrm{kb}$, and $\sim 4-\mathrm{kb}$ bands in cande $i$ with $\sim 9.4-\mathrm{kb}, \sim 5-\mathrm{kb}, \sim 2.8-\mathrm{kb}$, and $1.1-\mathrm{kb}$ in $v i$ tellinus) digests. All birds had either the vitellinus or candei patterns for all three mtDNA markers. A few individuals showed minor length variations in a single $\sim 5-\mathrm{kb} E c o \mathrm{R} V$ band, but haplotypes of all birds were clearly related to one or the other parental type (Parsons et al. 1993). Sample sizes and allele frequencies are given in Table 2.

To construct a summary measure of the degree of multilocus genetic admixture across the hybrid zone, a maximumlikelihood genetic hybrid index was estimated from the seven molecular marker loci using a Mathematica (Wolfram 1996) program written by S. J. E. Baird (Rieseberg et al. 1998). The index is calculated as the sum, over each individual's alleles, of the probability that the allele was derived from a vitellinus parental population instead of from a candei parental population (Rieseberg et al. 1998), scaled by the number of loci.

\section{Cline-Fitting Analysis}

The software package GENEPOP (Raymond and Rousset 1995) was used to perform probability tests for deviations from Hardy-Weinberg equilibrium (HWE) at each locus (using complete enumeration). For loci having more than four alleles, an unbiased approximation of the probability test for HWE was performed using a Markov-chain procedure. The computer program Analyse (Barton and Baird 1999) was used for analyses of cline structure. The shape of a cline can be modeled by combining three equations (Szymura and Barton 1986, 1991):

$$
\begin{gathered}
e^{X\left(\text { decay }_{c}\right)} \text { intercept }_{c}, \\
\frac{1}{1+e^{-4 X}}, \text { and } \\
1-e^{-X\left(\text { decay }_{v}\right)} \text { intercept }_{v},
\end{gathered}
$$

where decay $_{c}=2 \sqrt{\theta_{c}}$, decay $_{v}=2 \sqrt{\theta_{v}}$, intercept $t_{c}=t_{v} /\left(t_{c}+\right.$ $\left.t_{v}+t_{c} t_{v}\right)$, intercept $t_{v}=t_{c} /\left(t_{c}+t_{v}+t_{c} t_{v}\right), t_{c}=B_{c}$ decay $_{c}, t_{v}=$ $B_{v}$ decay $_{v}$, and $X=(x-c) / w$ is the distance $X$ along the cline scaled relative to the center and width. Equation (1b) is a sigmoid in the center, and equations (1a) and (1c) are exponential decay curves leading away from either side of the center. The change from the central curve (1b) to the exponential tails occurs at the point where the decay curves (1a and 1c) cross the sigmoidal curve (1b). This crossing point changes depending on the parameters. $\theta_{c}$ and $\theta_{v}$ are param- 

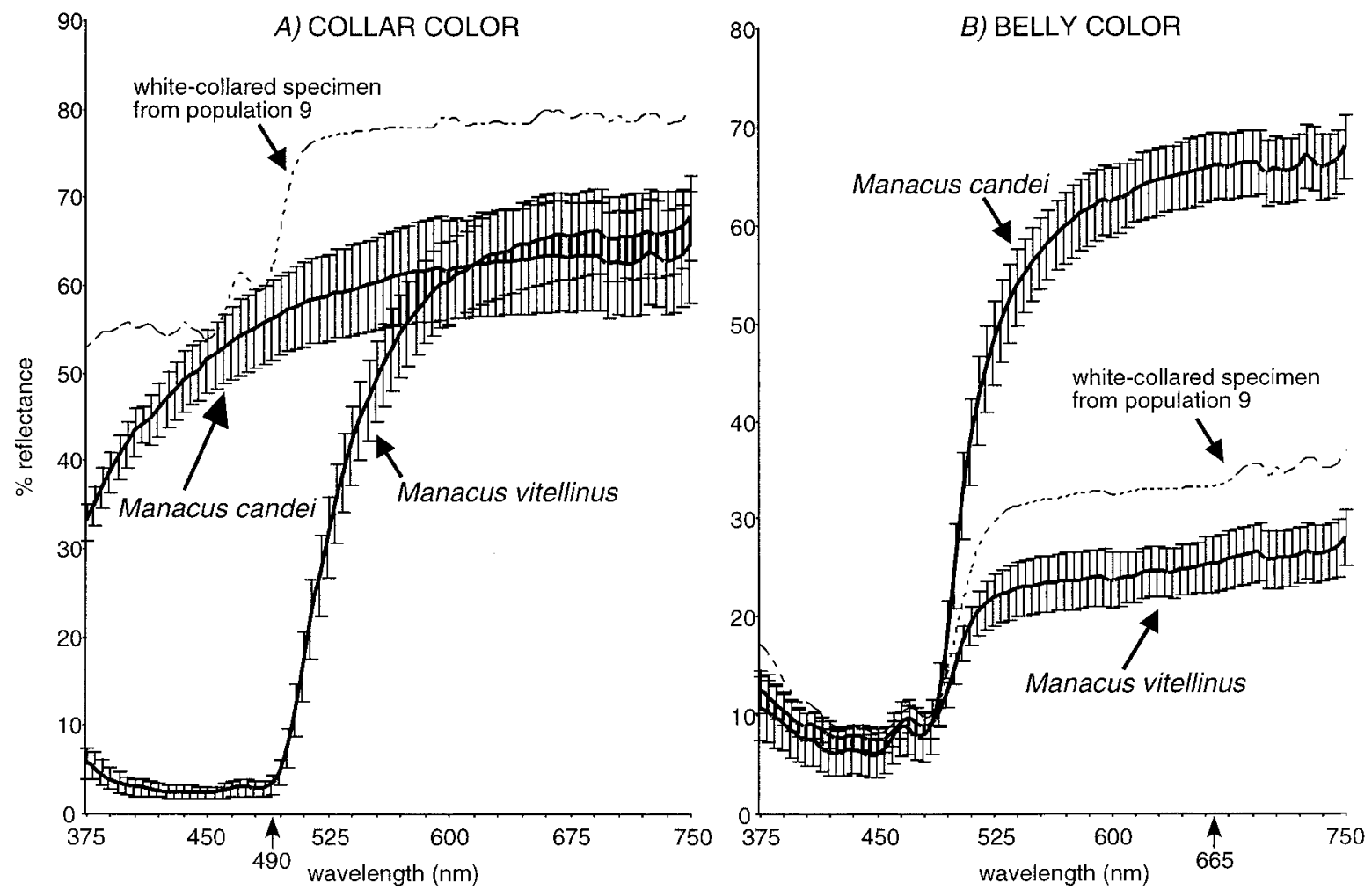

FIG. 2. Reflectance spectra for (A) collar color and (B) belly color in the reference samples of candei (population 1) and vitellinus (population 12). Mean measurements are presented along with standard deviations (error bars). We used the most divergent peaks, at percent reflectance of $490 \mathrm{~nm}$ and $665 \mathrm{~nm}$, to analyze collar- and belly-color variation across the hybrid zone. The dashed lines represent the spectra for an aberrant white-collared male (USNM 608981) collected in population 9, showing that it differs sharply from the typical candei spectra.

eters that describe the rate of exponential decay, and $B_{c}$ and $B_{v}$ describe the size of the central barrier to gene flow (Szymura and Barton 1986) in candei and vitellinus, respectively. The width of the cline $(w)$ is defined as $1 /$ maximum slope, $c$ is the central position of the cline where $p_{\text {est }}=0.5$, and $x$ is the distance $(\mathrm{km})$ from population 1 (Table 1). Two additional estimated parameters, $p_{\min }$ and $p_{\max }$, represent the frequencies at the two ends of the cline, and are used by Analyse to scale $p_{\text {est }}$ :

$$
p_{\text {est }}=p_{\min }+p_{\text {est }}\left(p_{\max }-p_{\min }\right) .
$$

Calculation of the likelihood of a fitted cline assumes a binomial sampling distribution for the molecular genetic markers. For each population, the support or goodness of fit for a fitted cline is expressed as a log-likelihood and is calculated as:

$$
\ln L=n\left[p_{o b s}\left(\frac{p_{o b s}}{p_{e s t}}\right)+\left(1-p_{o b s}\right)\left(\ln \frac{1-p_{o b s}}{1-p_{e s t}}\right)\right],
$$

where $n$ is the number of alleles sampled in the population, $p_{o b s}$ is the observed frequency of the modeled allele and $p_{e s t}$ is the estimated frequency of the modeled allele based on Equation (1). The support for the entire fitted cline is the sum of the population log-likelihoods.

Goodness-of-fit tests were performed to identify, for each locus, a cline model that best describes the data with the fewest number of estimated parameters. In model I, only $c$ (center of cline) and $w$ (width) were estimated from the data. $\theta_{c / v}$ and $B_{c / v}$ were assumed to be one and zero, respectively, on both sides of the cline, and the ends of the cline were fixed to the maximum $\left(p_{\max }\right)$ and minimum $\left(p_{\min }\right)$ observed allele frequencies. Model II included the $c$ and $w$ parameters plus estimates of the allele frequencies $\left(p_{\min }\right.$ and $p_{\max }$ ) at the two ends of the cline. In Model III, $\theta_{c / v}$ and $B_{c / v}$ were also allowed to vary. Model parameters were estimated by a bounded, directional search of the parameter space using the Metropolis-Hastings algorithm (Metropolis et al. 1953; Hastings 1970) implemented in Analyse. Three thousand iterations were run from 20 different starting points. The test statistic was calculated as two times the absolute difference in log-likelihood between the models under comparison. Significance $(\alpha=0.05)$ was determined by comparison to the $\chi^{2}$-distribution, with the degrees of freedom equivalent to the difference in the number of estimated parameters between the two models (Table 3).

Model II provided the best fit for all loci except $A d a^{a}$ and $\lambda 5^{b}$. The best fit for $A d a^{a}$ was provided by model I, for which only center $(c)$ and cline width $(w)$ are estimated. Model III provided the best fit for $\lambda 5^{b}$, primarily because the cline decays exponentially in frequency on the eastern side of the hybrid zone. Using the best-fit model for each locus (Table 3 ), parameters were estimated by running 30,000 iterations of the Metropolis-Hastings algorithm with 20 different starting points. Except for Ada, all 20 searches converged on the 
TABLE 2. Allele frequencies and $F_{\text {IS }}$ estimates for each population at each locus. Sample sizes are presented for diploid (2n) and haploid ( $n$ ) loci.

\begin{tabular}{|c|c|c|c|c|c|c|c|c|c|c|c|c|c|c|c|c|}
\hline \multirow[b]{2}{*}{ Population } & \multirow{2}{*}{$\begin{array}{l}\text { Distance } \\
(\mathrm{km})\end{array}$} & \multicolumn{4}{|c|}{$A d a$} & \multicolumn{4}{|c|}{$A k-2$} & \multicolumn{7}{|c|}{ Gsr } \\
\hline & & a & $\mathrm{b}$ & $2 n$ & $F_{\text {IS }}$ & a & $\mathrm{b}$ & $2 n$ & $F_{\text {IS }}$ & a & $\mathrm{b}$ & $\mathrm{c}$ & d & e & $2 n$ & $F_{\text {IS }}$ \\
\hline 1 & 0 & 0.100 & 0.900 & 10 & - & 0.000 & 1.000 & 10 & - & 0.000 & 0.100 & 0.900 & 0.000 & 0.000 & 10 & - \\
\hline 2 & 138.25 & 0.357 & 0.643 & 14 & +0.143 & 0.143 & 0.857 & 14 & -0.091 & 0.000 & 0.000 & 0.929 & 0.000 & 0.071 & 14 & - \\
\hline 4 & 159.5 & 0.450 & 0.550 & 40 & +0.216 & 0.025 & 0.975 & 40 & - & 0.075 & 0.075 & 0.850 & 0.000 & 0.000 & 40 & +0.087 \\
\hline 5 & 182.25 & 0.310 & 0.690 & 42 & +0.243 & 0.024 & 0.976 & 42 & - & 0.048 & 0.024 & 0.905 & 0.024 & 0.000 & 42 & -0.046 \\
\hline 6 & 188.25 & - & - & 0 & - & - & - & 0 & - & - & - & - & - & - & 0 & - \\
\hline 10 & 230.75 & 0.625 & 0.375 & 40 & -0.365 & 0.975 & 0.025 & 40 & - & 0.000 & 0.225 & 0.425 & 0.350 & 0.000 & 40 & +0.250 \\
\hline 11 & 319.5 & 0.425 & 0.575 & 40 & +0.105 & 0.895 & 0.105 & 38 & -0.091 & 0.000 & 0.450 & 0.375 & 0.175 & 0.000 & 40 & -0.173 \\
\hline 12 & 569.5 & 0.675 & 0.325 & 40 & +0.227 & 1.000 & 0.000 & 40 & - & 0.000 & 0.225 & 0.725 & 0.050 & 0.000 & 40 & +0.194 \\
\hline
\end{tabular}

same parameters, consistent with a single likelihood peak. Two-unit log-likelihood support values $\left(\ln L_{\max }-2\right)$ were obtained for each fitted cline by an additional 2000 iterations of the Metropolis-Hastings search.

Equation (1) was used to fit clines for the morphological characters (Butlin et al. 1991). Log-likelihood support values ( $\ln L$ ) were not calculated, because the sampling distribution of the morphological characters could not be reliably assumed normal, as required by Analyse for treatment of quantitative traits. Because goodness-of-fit model tests were not possible, the most general model (model III) was used for all morphological cline fits. Before clines were fit to the morphological character population means, individual measurements were scaled to values between zero and one. All fitted clines are illustrated so that vitellinus has the largest character value. For example, because the percent reflectance at $490 \mathrm{~nm}$ is greater in white-collared candei, a cline was fit to $100-\%$ reflectance so that vitellinus had a larger value on the eastern side of the cline. This provides a cosmetic improvement for qualitatively comparing cline shapes.

\section{RESULTS}

\section{Molecular Variation and Cline Shape}

Parental populations showed strong allele frequency differences at all molecular marker loci (Table 2), but only mtDNA and $A k-2$ reached fixation for alternative alleles in both parental populations. $\lambda 5$ and pSCN3 were fixed in parental vitellinus (population 12) and nearly fixed in parental candei (population 1), so we treat them tentatively as diagnostic herein. $F_{\text {IS }}$-values were not significantly different from zero in any population, consistent with HWE. Individual genotypic data indicate that the majority of individuals in population 9 were of hybrid origin (Brumfield 1999).

All molecular loci except Ada have steep clines of the same approximate width $(w=2.9-11.1 \mathrm{~km})$ that are centered in the same general position ( $c=206.5-209.9)$, a few kilometers west of population 9 (Fig. 3, Table 4). Patterns of variation were most straightforward at $A k-2, \lambda 5, \mathrm{pSCN} 3$, and mtDNA, the four loci having fixed or nearly fixed alternate alleles in candei and vitellinus. Each of these loci was char- acterized by steep transitions near population 9, with more or less monotonic change across the hybrid zone (Fig. 3A). Low frequencies of the "wrong", alleles in populations 1-6 and 10-11 probably represent shallow tails of introgression at these loci, because the frequencies decline to near zero in populations 1 and 12. Gsr and Pgm-2 also underwent steep transitions near population 9 (Fig. 3B). Relatively high frequencies of several alleles at these loci in populations 1012 may be due to polymorphism in parental vitellinus populations rather than introgression. In contrast, Ada exhibited a broad cline across the entire transect (Fig. 3B).

The transition in genetic hybrid index scores of individuals (Fig. 4A) reflects a steep gradient in allele frequencies near population 9 (Table 2). Population 10, situated $21 \mathrm{~km}$ southeast of population 9, is entirely composed of individuals whose genetic index scores are similar to those found in parental vitellinus (population 12) more than $350 \mathrm{~km}$ farther east. Population 8 , located $9 \mathrm{~km}$ to the north of population 9 , is composed of candei-like individuals, with the exception of two individuals having intermediate scores. As expected, there were more vitellinus-like than candei-like individuals in population 9, because the sample is situated $0.5-3.5 \mathrm{~km}$ southeast of the estimated hybrid zone center.

\section{Statistical Comparisons of Molecular Clines}

Six molecular clines agreed remarkably well in position and width, but the maximum-likelihood estimates for Ada differed substantially from all other loci (Table 4). Maximum likelihood provides a framework in which to compare clines statistically when the mode of inheritance is known (Edwards 1972). We performed a $G$-test of the null hypothesis that all loci are compatible with a single null cline center position (Rao 1973). To determine the null log-likelihood, log-likelihoods were calculated over a series of 13 potential null points chosen to span the observed range in cline centers (Table 5). Separate Metropolis-Hastings searches were performed for each locus using the appropriate optimized model and parameter values (Table 4), but with $c$ fixed at one of the 13 potential null cline centers. The null log-likelihood used in the test was the maximum log-likelihood of the 
TABLE 2. Extended.

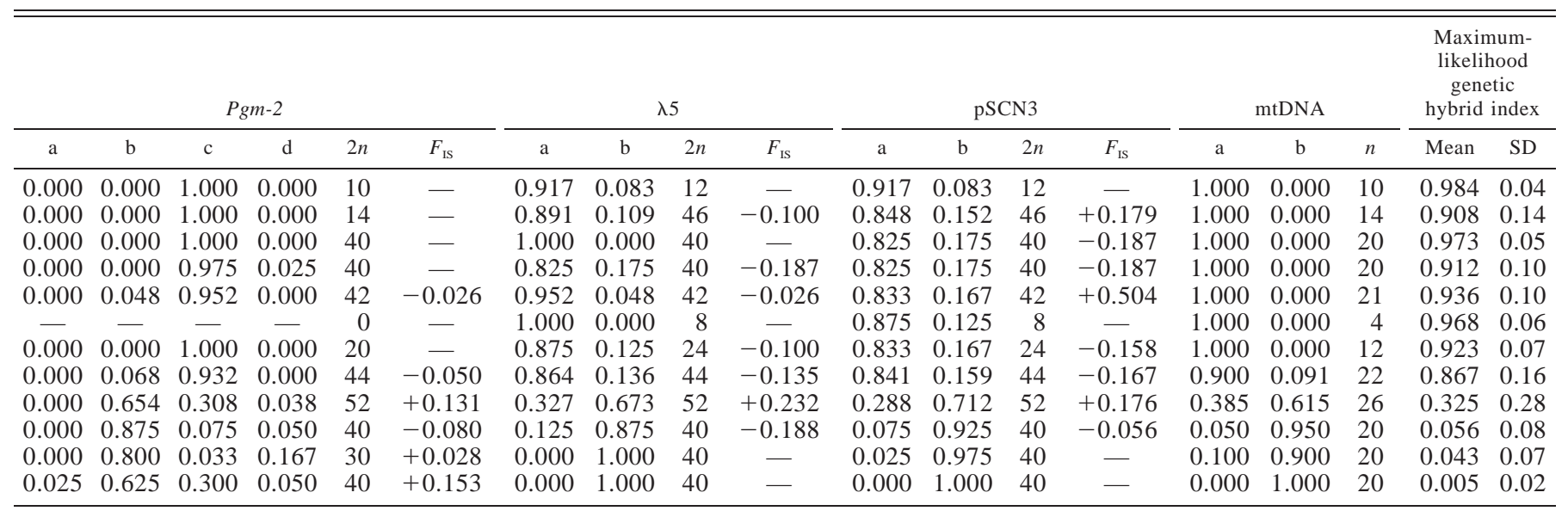

searches from this set, in this case $-43.6(c=208.2 \mathrm{~km})$. If there are significant differences in cline position, this null log-likelihood will be significantly worse than the overall log-likelihood $(-38.7)$ calculated from an unconstrained search. The test statistic is calculated as the absolute difference between the two log-likelihoods (constrained and unconstrained), multiplied by two. Significance is evaluated by comparison to a $\chi^{2}$-table, with the degrees of freedom equivalent to (number of loci -1 ). The null hypothesis that all loci have a common center was not rejected $\left(\chi^{2}=9.8\right.$, df $=$ $6)$, indicating that the Ada cline is consistent with the position of the other genetic clines, given available data. The fact that its estimated center is approximately $40 \mathrm{~km}$ northwest of the others (Table 4) may simply be due to variability in the $A d a$ data.

Using the same methodology, we performed a test to detect significant differences in cline width. To determine the null log-likelihood, log-likelihoods were calculated over a range of cline widths that encompassed the observed variation (Table 6). The null hypothesis that all loci have the same cline width was rejected $\left(\chi^{2}=44.8, \mathrm{df}=6\right)$. To determine whether Ada was responsible for the significant test, we performed a second test, but with Ada excluded. In this test, the null was not rejected $\left(\chi^{2}=4.8\right.$, df $\left.=5\right)$. Thus, we infer that cline width is not significantly different among loci except for $A d a$, which is wider. Maximum-likelihood confidence limits on

TABLE 3. Log-likelihood scores for fitted clines under different models. See Materials and Methods for descriptions of models and goodness-of-fit tests. An asterisk denotes the model that provides the best fit with the fewest number of estimated parameters.

\begin{tabular}{lccc}
\hline \hline \multicolumn{1}{c}{ Locus } & $\begin{array}{c}\ln L \\
\text { Model I } \\
\text { (parameters = 2) }\end{array}$ & $\begin{array}{c}\ln L \\
\text { Model II (ln } L) \\
(\text { parameters = 4) }\end{array}$ & $\begin{array}{c}\ln L \\
\text { Model III (ln } L) \\
(\text { parameters = 8) }\end{array}$ \\
\hline$A d a^{a}$ & $-9.6^{*}$ & -8.3 & -7.9 \\
$A k-2^{a}$ & -43.9 & $-6.2^{*}$ & -6.2 \\
$P g m-2^{b}$ & -17.7 & $-6.7^{*}$ & -6.7 \\
$G s r^{b}$ & -15.7 & $-5.8^{*}$ & -5.0 \\
$\lambda 5^{b}$ & -36.9 & -12.2 & $-6.6^{*}$ \\
pSCN3 $^{b}$ & -17.9 & $-2.6^{*}$ & -1.2 \\
mtDNA $^{b}$ & -19.1 & $-1.8^{*}$ & -1.8 \\
\hline
\end{tabular}

the Ada cline width estimate are very large (Table 4), again due to variability in the data.

\section{Morphological Variation and Cline Shape}

The clines for PC1 (Fig. 4B) and beard length (Fig. 5A) were similar in position (Table 7) to the genetic clines (Table $4)$. Because it is composed of four mensural variables with similar factor loadings, PC1 is closely related to overall size. Average PC1 scores changed from candei-like in populations $1-8$ to vitellinus-like in populations $10-12$ (Fig. 4B). PC1 scores in populations $1-8$ were not significantly different (one-way ANOVA, $F=1.2, P>0.05$ ). An ANOVA of populations $1-9$ was significant $(F=6.5, P<0.0001)$ due to the morphological intermediacy of hybrid individuals in population 9 . The epaulet width cline was broader (Fig. 5A) and its center several kilometers northwest of the other cline centers (Table 7), but the estimate was near the minimum two log-likelihood unit support limit for some of the genetic clines (Table 4).

In contrast to the molecular and morphometric character clines, the two plumage color clines (Fig. 5B) have steep transitions centered about $50 \mathrm{~km}$ northwest of the other cline centers. The clines are narrow, with estimated widths of 3.0 and $4.4 \mathrm{~km}$ (Table 7). In both cases, the most dramatic change in color occurs between populations 3 and 4, which are only 8 $\mathrm{km}$ apart, but which lie on opposite banks of the Changuinola River. Eighty-five percent of the change in mean collar color occurs across the Changuinola River, with the remaining $15 \%$ between populations 4 and 10. Qualitatively, collar color changes abruptly from white in population 3 to lemon yellow in population 4 , then subtly over the next $70 \mathrm{~km}$ to golden yellow in population 10. Belly color changes from lemon yellow at population 3 to a drab green at population 10, with much the same trajectory. Fifty-four percent of the total change in mean belly color occurs across the Changuinola River.

\section{Statistical Evaluation of Cline Shifts}

Statistical significance of the color cline shifts was evaluated with a nonparametric bootstrap approach (Efron and 


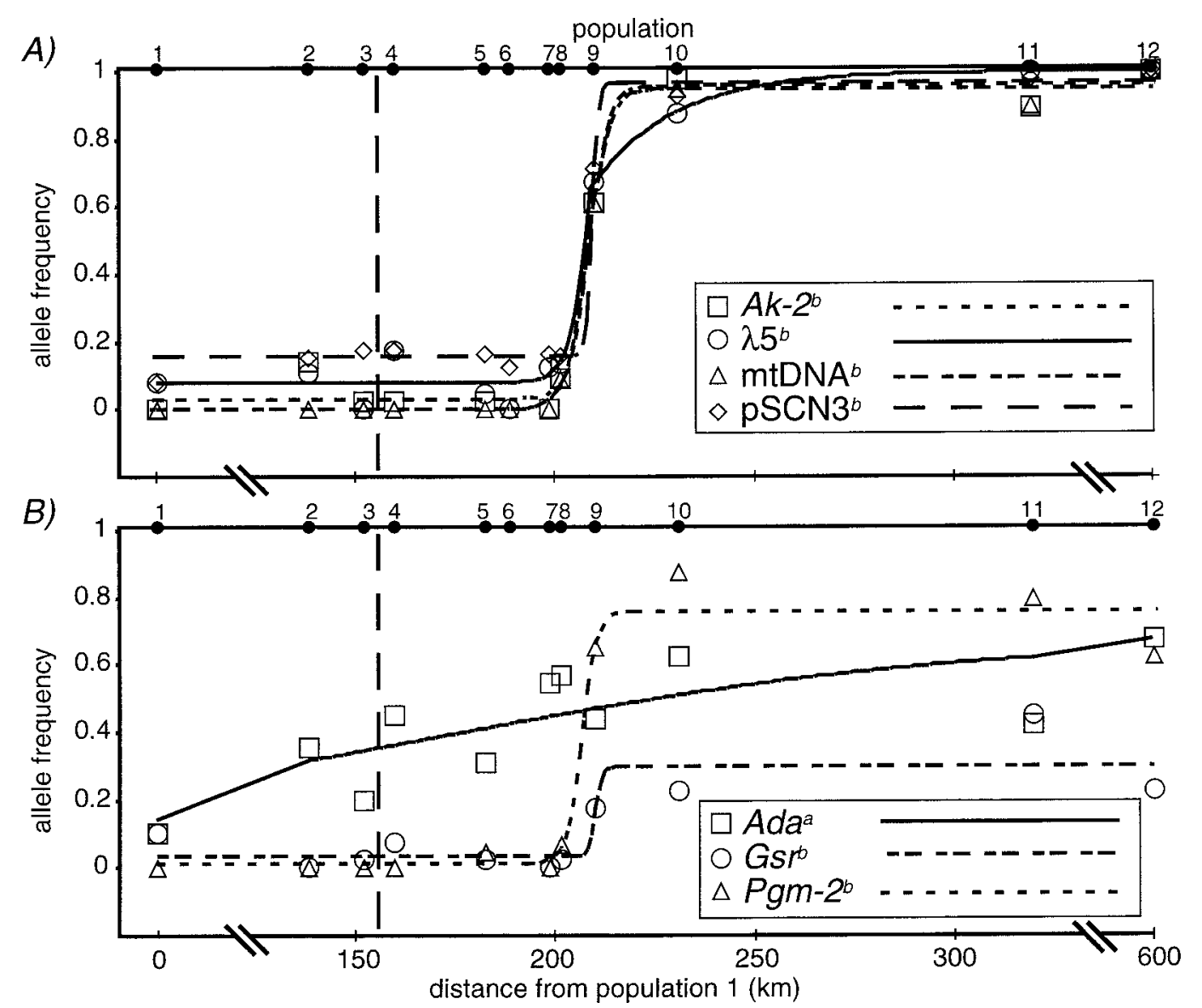

FIG. 3. Clines, fit by maximum likelihood, for (A) the four genetic markers with fixed or nearly fixed alternate alleles in each form and (B) the three genetic markers that differed in allele frequency between the two forms. Symbols indicate observed allele frequencies. The vertical dashed line indicates the position of the Changuinola River. Railroad bars on the $x$-axis denote a nonlinear break in geographic distance.

Tibshirani 1993) using smoothing splines (Schluter 1988). This has the advantages of speed and flexibility, and, more importantly, is not constrained by any particular sampling distribution. For individual collar and belly color measurements, 200 bootstrap samples were taken at each population. Generalized cross-validated smoothing splines were then fit using S-plus (MathSoft 1999) to the resulting bootstrap sample means weighted by the inverse of the bootstrap sample variances. The 200 resulting curves were used to estimate 200 sample cline centers as the point of steepest slope on each curve. The distribution of these 200 cline centers models the variability in position among the color bootstrap samples.

To compare the color clines to the molecular clines, 200 bootstrap samples of each genetic marker were generated using a binomial model with probability of success being the observed gene frequency at each population. Generalized cross-validated smoothing splines were then fit to the resulting logit transformed bootstrap sample means weighted by the inverse of the estimated logit variances. The fitted smoothing splines were transformed back to a cline of estimated gene frequencies. As in the color data, these 200 resulting curves were used to estimate 200 sample cline positions as the point of steepest slope of each curve. The dis- tribution of these 200 cline centers models the variability in position among the molecular bootstrap samples.

The statistical significance of the shifted positions of the color clines was assessed using $P$-values given by the percentage of the bootstrap color cline positions that occur outside the distribution of the bootstrap genetic cline positions. We found that all of the 200 bootstrap samples for both collar and belly color had cline positions outside the distribution of the 200 bootstrap samples of all genetic markers except Ada (Fig. 6). Thus, sampling variability alone cannot account for the shifted plumage color clines. The broad distribution of Ada is consistent with the large confidence intervals on its cline position estimate (Table 4). An analogous bootstrap analysis of the epaulet width cline indicated that its position is not significantly shifted.

\section{DiscUSSION}

Our results demonstrate that an array of six molecular and two morphometric markers agree in cline position and width and define the center of the hybrid zone within a few kilometers of population 9. These include markers of the nuclear and mtDNA genome, assayed by both allozyme and restric- 
TABLE 4. Likelihood support and parameter estimates for the genetic clines. Two log-likelihood unit support limits are presented in parentheses. For comparison, two measures of cline width are presented: 1/maximum slope $(w)$, and distance between $20 \%$ and $80 \%$ points ( $w 1)$. Parameter $c$ is the cline center measured in distance $(\mathrm{km})$ from population $1, p_{\min }$ is the minimum estimated frequency at the west end of the cline, $p_{\max }$ is the maximum estimated frequency at the eastern end, $B$ and $\theta$ are shape parameters for the exponential decay curves. Numbers in bold are parameters reoptimized after excluding population 6 (no value is presented in cases where the reoptimized parameter was identical).

\begin{tabular}{|c|c|c|c|c|c|c|c|}
\hline & $A d a^{\mathrm{a}}$ & $A k-2^{\mathrm{a}}$ & $P g m-2^{\mathrm{b}}$ & $G s r^{\mathrm{b}}$ & $\lambda 5^{b}$ & $\mathrm{pSCN}^{b}$ & $\mathrm{mtDNA}^{b}$ \\
\hline $\ln L$ & -9.6 & -6.2 & -6.7 & -5.8 & $\begin{array}{l}-6.6 \\
-\mathbf{5 . 9}\end{array}$ & -2.6 & -1.9 \\
\hline$w$ & $\begin{array}{c}262.5 \\
(110.0-856.4)\end{array}$ & $\begin{array}{c}9.9 \\
(0.9-15.3)\end{array}$ & $\begin{array}{c}7.7 \\
(0.5-12.0)\end{array}$ & $\begin{array}{c}2.9 \\
(0.2-37.9)\end{array}$ & $\begin{array}{c}10.4 \\
(7.2-14.4)\end{array}$ & $\begin{array}{c}2.8 \\
(0.6-15.4) \\
\mathbf{3 . 9}\end{array}$ & $\begin{array}{c}11.1 \\
(6.9-19.0)\end{array}$ \\
\hline$w 1$ & 204.9 & 6.9 & 5.50 & 4.4 & 11.6 & 4.9 & 7.7 \\
\hline$c$ & $\begin{array}{c}171.0 \\
(108.7-200.1)\end{array}$ & $\begin{array}{c}208.6 \\
(207.3-210.2)\end{array}$ & $\begin{array}{c}206.5 \\
(201.5-209.5)\end{array}$ & $\begin{array}{c}209.9 \\
(202.1-223.1)\end{array}$ & $\begin{array}{c}208.2 \\
(206.2-208.4) \\
\mathbf{2 0 8 . 3}\end{array}$ & $\begin{array}{c}209.4 \\
(206.7-209.9) \\
\mathbf{2 0 9 . 3}\end{array}$ & $\begin{array}{c}208.3 \\
(206.4-210.3) \\
\mathbf{2 0 8 . 2}\end{array}$ \\
\hline$p_{\max }$ & $\begin{array}{l}0.675 \\
\text { (fixed) }\end{array}$ & $\begin{array}{c}1.0 \\
(1.0-1.0)\end{array}$ & $\begin{array}{c}0.8 \\
(0.7-0.8)\end{array}$ & $\begin{array}{c}0.3 \\
(0.2-0.4)\end{array}$ & $\begin{array}{c}1.0 \\
(1.0-1.0)\end{array}$ & $\begin{array}{c}1.0 \\
(0.9-1.0)\end{array}$ & $\begin{array}{c}0.9 \\
(0.9-1.0)\end{array}$ \\
\hline$B_{c}$ & 0 & 0 & 0 & 0 & $\begin{array}{c}1535.9 \\
(1520-1556) \\
\mathbf{3 2 1 7 . 5}\end{array}$ & 0 & 0 \\
\hline$\theta_{c}$ & 1 & 1 & 1 & 1 & $\begin{array}{c}1.0 \\
(0.2-1.0) \\
\mathbf{0 . 9}\end{array}$ & 1 & 1 \\
\hline$\theta_{v}$ & 1 & 1 & 1 & 1 & $\begin{array}{c}0.1 \\
(0.0-0.1)\end{array}$ & 1 & 1 \\
\hline
\end{tabular}

tion-fragment-length-polymorphism analysis, and one marker, PC1, that integrates four morphometric characters. Two other clines, $A d a$ and epaulet width, are similar in position, but broader in width. Finally, two male plumage color clines, collar color and belly color, are similar in width to the first eight clines, but are shifted in position by at least five cline widths. These results confirm and extend the observations of Parsons et al. (1993). The two phenotypic clines in male plumage color are shifted by about $50 \mathrm{~km}$ away from the genetically and morphometrically defined hybrid zone to the banks of the Changuinola River, between populations 3 and 4. The result is that birds in populations $4-8$ are genetically and morphometrically very like parental candei, but their yellow collars and greenish bellies make them appear superficially like parental vitellinus.

Butlin and Neems (1994) suggested that the apparent shift of Manacus color clines might be an artifact of (1) greater cline width; (2) nonlinear color scales; or (3) genetic dominance of vitellinus traits. To address the first two possibilities, we measured color quantitatively using a reflectance spectrophotometer, sampled two new populations ( 8 and 9) near the center of the hybrid zone, increased the sample size of other populations, and made statistical tests of cline shifts. The spectrophotometric measurements show even more dramatic shifts in color than was evident in the semiquantitative scale previously employed. Fully $85 \%$ of the change in mean collar color and $54 \%$ of the change in mean belly color occurs across the Changuinola River. The increased sampling provides greater resolution near the center of the hybrid zone, revealing that most of the genetic and morphometric clines are in fact narrower than could be demonstrated with the previous data. The statistical comparisons show unequivocally that the collar and belly color cline centers are shifted significantly. The net effect of these refinements is to reveal that the collar and belly color clines are actually shifted about $10 \mathrm{~km}$ further west than the minimum estimated by Parsons et al. (1993).

We did not examine a third potentially shifted cline, that for collar width (Parsons et al. 1993), because we found that the character was unduly influenced by the style of specimen preparation. Instead, we substituted epaulet width, which appears to be correlated with collar width (at least in parental populations) and can be measured more accurately (Brumfield 1999). We found the epaulet width cline to be broader, but not shifted significantly away from the genetic and morphometric clines. This may indicate that the concerns of Butlin and Neems (1994) about the collar width cline were well founded. However, collar width is a relatively minor character; collar and belly color have much greater influence on male appearance.

Several methods have been used to test for differences in cline structure. Simple approaches involve testing for homogeneity of allele frequencies among loci or among populations on a transect (Dod et al. 1993; Parsons et al. 1993; Jaarola et al. 1997). These approaches are limited in the aspects of cline structure examined and use only a fraction of the relevant data. Several techniques attempt to use more data by modeling cline structure with fitted curves (Szymura and Barton 1986; Tucker et al. 1992; Barton and Baird 1999). These approaches are constrained by the requirements of using a fixed mathematical form or assuming a particular mode of inheritance. Smoothing splines provide a flexible approach to curve fitting without requiring a fixed mathematical form. In effect, our approach allows the data to determine the form that best describes them. The nonparametric bootstrap allows for statistical comparisons among clines where the mode of 


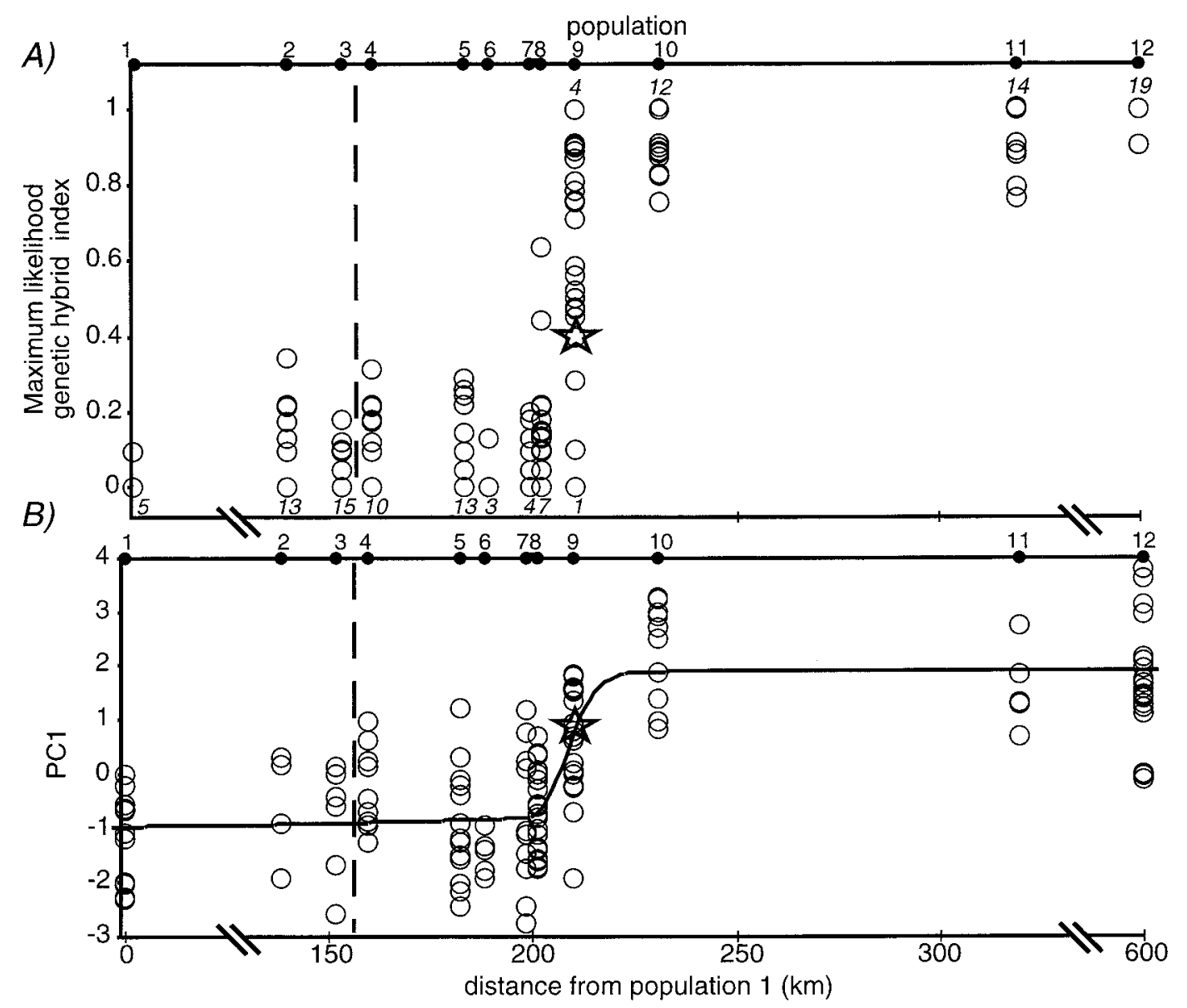

FIG. 4. Individuals scores in each population for (A) the maximum-likelihood genetic hybrid index of seven loci and (B) the first principal component axis (PC1) integrating four morphometric characters (mass, wing length, tail length, tarsus length). For the genetic index, the number of individuals having scores of 0 or 1 is in italics. The starred individual is a male (USNM 608981) from population 9 with aberrant plumage color. The vertical dashed line indicates the position of the Changuinola River. Bars on the $x$-axis denote a nonlinear break in geographic distance.

inheritance is not known. This flexibility is crucial in the present case, where we compare phenotypic plumage color clines to allele frequency clines at molecular loci.

The possibility that genetic dominance of vitellinus color traits could cause the phenotypic clines to be shifted, when the underlying allele frequency clines are in fact coincident, is more difficult to eliminate. In both Dendroica warbler (Rohwer and Wood 1998) and Gymnorhina magpie hybrid zones (Hughes 1982), genetic dominance at one or a few hypothetical plumage trait genes were invoked as potential explanations for the shifted clines observed in those zones. Ultimately, crossing experiments would be required to address directly the mode of inheritance of the plumage traits in Manacus. Such experiments will be difficult to perform in lek-mating birds (we have tried).

It is useful to consider the number of loci and allele frequencies required by a dominance hypothesis to account for the observed phenotypic frequencies (Parsons et al. 1994). Under a model of dominant vitellinus color traits, white-collared males would most likely be observed at population 4, near the source of candei alleles. We have now observed more than 200 males in the region of populations 4-8, many individually marked and released, and have never detected a typical white-collared male (Parsons et al. 1994; McDonald et al. 2001). Thus, the observed frequency of white-collared males is less than 0.005. If we assume a simple model in which collar color is controlled by a series of unlinked loci, and that dominant vitellinus alleles occur at all loci at a frequency of 0.2 , about 12 loci would be required to account for the observed phenotypic frequency $\left.\left[(0.8)^{2}\right]^{12}=0.0047\right)$. These are generous assumptions considering the average frequency of diagnostic vitellinus molecular markers at population 4 is 0.094 (range $0.000-0.175$ ). Given the uniformity in the widths of the clines for the other diagnostic molecular and morphological markers, it seems more plausible to suppose that the plumage color clines are also narrow, but shifted. This interpretation is consistent with available studies documenting that similar plumage traits in other birds are under the control of relatively few genes (Johnson and Brush 1972; Buckley 1987; Rohwer and Wood 1998).

We have found only a single white-collared male in the transect populations east of the Changuinola River that might conceivably represent a homozygous recessive recombinant. In 1994, a white-collared specimen (USNM 608981) was 
collected at population 9, near the center of the genetic and morphological clines. The bird is aberrant in that the reflectance of its white collar plumage is uniformly higher than in parental candei (Fig. 2), and its belly is drab green suffused with yellow streaks, typical of other males in population 9, but unlike the lemon yellow belly color of candei. Other than its white collar, the specimen is characteristic of other introgressed individuals in population 9, with intermediate PC1 and maximum-likelihood genetic hybrid index scores (see starred individual in Fig. 4). Because the specimen was collected far from population 4, where white-collared homozygous recessive birds are most likely under the dominance hypothesis, it is unclear whether the specimen is white-collared because it is homozygous recessive or because it is a mutant. The disruption of coadapted gene complexes that could cause such a mutation (Woodruff 1989) is expected to be highest in population 9, at the hybrid zone center.

At this point, the dominance hypothesis seems less likely because the cline shifts are much greater (about five cline widths) than would be expected under simple models of dominance (Endler 1977) and because the homozygous recessive white-collared birds expected under this hypothesis are not observed at a plausible frequency in populations 4-8 (Parsons et al. 1994). In addition, a potential behavioral correlate of sexual selection on male plumage color has now been observed (McDonald et al. 2001). Experiments involving the presentation of taxidermic mounts to males on leks found that lemon- or golden-collared males, regardless of location, were significantly more aggressive than were white-collared males. Heightened aggression could conceivably translate into increased mating success for yellow-collared males in mixed leks (McDonald et al. 2001).

\section{Evolutionary Implications of Shifted Clines}

The majority of hybrid zone studies report cline transitions that coincide in position (Barton and Hewitt 1985). Relatively few cases have been reported where clines are noncoincident, although such reports seem to be increasing (Barton 1993; Jaarola et al. 1997). This increase may be due to larger numbers of clines being characterized per study and the increased use of molecular and chromosomal markers. Jaarola et al. (1997) reviewed examples of noncoincident clines and discussed potential mechanisms that might cause cline displacement. Such cases may be roughly divided into two types (Barton 1993); those characterized by staggered clines, where an array of individual character clines are shifted slightly away from each other, and those due to asymmetric introgression of one or a few characters beyond the limits of the hybrid zone. The Manacus case is an example of the latter.

The large cline shifts found in cases of asymmetric introgression might be explained by neutral introgression, movement of the zone, founder effect, or selective advantage. In the Manacus zone, the magnitude of the cline shift appears to be greater than can be explained by neutral processes alone. Although clines can be displaced by genetic drift given sufficient population subdivision, the displacement is not expected to exceed one cline width (Barton 1983). Moreover, there is probably little population subdivision among manakins of populations 4-8. Early successional forest and aban- 
TABLE 6. G-test of the null hypothesis that all loci have the same cline width. Matrix entries are the log-likelihood support values (ln $L_{c}$ ) for an analysis in which $w$ is constrained to one of the eight null values $(w=2.0-62.0 \mathrm{~km})$. These widths were examined because they span the range of observed cline widths, with the exception of Ada. Larger cline widths were examined, but all produced increasingly worse loglikelihoods. $\ln L_{u}$ is the unconstrained $\log$-likelihood support. Using the maximum overall $\ln L_{c}$ as the null value (i.e., -61.1 ), the null hypothesis that the seven cline widths are the same is rejected $\left(\chi^{2}=44.8, \mathrm{df}=6\right)$. Repeating this analysis with Ada excluded results in a loss of significance $\left(\chi^{2}=4.8, \mathrm{df}=5\right)$, indicating that the cline for $A d a$ is significantly wider. The critical $\chi^{2}$-value for five degrees of freedom is 11.1 .

\begin{tabular}{|c|c|c|c|c|c|c|c|c|c|}
\hline Cline width $(w)$ & 2.0 & 7.0 & 12.0 & 17.0 & 22.0 & 32.0 & 42.0 & 62.0 & $\ln L_{u}$ \\
\hline Ada & -30.1 & -29.7 & -28.5 & -28.0 & -27.5 & -25.5 & -22.2 & -16.0 & -9.6 \\
\hline$A k-2$ & -7.2 & -6.7 & -6.6 & -8.8 & -11.7 & -17.6 & -23.5 & -33.4 & -6.2 \\
\hline Gsr & -5.8 & -5.8 & -6.2 & -6.7 & -7.1 & -7.5 & -7.7 & -8.4 & -5.8 \\
\hline$\lambda 5$ & -6.0 & -6.0 & -6.0 & -6.5 & -9.3 & -13.5 & -15.8 & -21.6 & -5.9 \\
\hline pSCN3 & -2.6 & -2.6 & -3.4 & -5.1 & -6.6 & -8.9 & -11.8 & -17.2 & -2.6 \\
\hline mtDNA & -4.8 & -3.6 & -1.9 & -3.0 & -4.4 & -7.5 & -10.7 & -16.7 & -1.9 \\
\hline$\Sigma \ln L($ with $A d a)$ & -64.0 & -61.2 & -61.1 & -70.0 & -81.1 & -98.9 & -114.5 & -145.1 & -38.7 \\
\hline$\Delta=\left[\Sigma \ln L_{c}-\Sigma \ln L_{u}\right]($ w/o $A d a)$ & 4.8 & 2.4 & 3.5 & 12.9 & 53.6 & 73.4 & 92.3 & 129.1 & \\
\hline$\chi^{2}=2 \Delta$ (with $\left.A d a\right)$ & 50.6 & 45.0 & $44.8 *$ & 62.6 & 84.8 & 120.4 & 151.6 & 212.8 & \\
\hline$\chi^{2}=2 \Delta($ w/o $A d a)$ & 9.6 & $4.8^{*}$ & 7.0 & 25.8 & 107.2 & 146.8 & 184.6 & 258.2 & \\
\hline
\end{tabular}

doned cacao plantations occur almost continuously throughout the region, and manakins are abundant in these habitats. It would be hard to exclude movement of the zone as an explanation for the shifted clines without longer-term temporal information. Analyses of historical specimens suggest an eastward shift of the hybrid zone over the past 100 years on the order of several kilometers, except for collar color, which has shifted northwestward (R. T. Brumfield, unpubl. data).

The Manacus case is an unusual example of asymmetric introgression because it involves secondary sexual traits, which are likely to play a role in mating success in these highly sexually dichromatic lek-mating species. Selection for vitellinus traits remains a plausible explanation for the shifted clines. Females of both species could preferentially mate with yellow-collared males, or yellow-collared males could outcompete white-collared males within leks. The greater aggression of both golden- and lemon- versus white-collared males in male-male interactions may confer a selective advantage (McDonald et al. 2001). Thus, selection may be acting directly on male aggression, with male plumage color introgressing as a correlated trait (Rohwer et al. 2001).

Other possible advantages of yellow collars involve environmental gradients in light regime. Fitness differences could relate to visibility differences among male plumage types in the forest understory. Recent studies of other manakin species have shown that the conspicuousness of brightly plumaged males varies with the background light regime (Endler and Théry 1996). Under this hypothesis, a light regime gradient along which male candei and vitellinus are not equally conspicuous could lead to displaced color clines (Hewitt 1988). Although forest composition is superficially similar along the transect, this possibility needs to be examined.

If vitellinus color traits are under positive selection, it is puzzling that they have not yet progressed to fixation. Because selected traits are expected to sweep rapidly to fixation, it is unusual to observe a sweep in progress. One possibility is that the Rio Changuinola, where the plumage color clines are centered, is a barrier to the spread of the traits. Using data from microsatellite loci, Brumfield (1999) found that genetic differentiation among populations across the river is greater than that on either side, suggesting that the river is a significant barrier to the movement of individuals. The barrier is clearly not impenetrable, however, because vitellinus alleles $\left(\lambda 5^{b}, \mathrm{pSCN} 3^{b}\right)$ have been detected in populations west of the river. The hypothesized selection for vitellinus color traits might be frequency dependent, which would accentuate the effect of a river barrier in obstructing introgression.

Why the genetic and morphometric clines are centered where they are also remains unclear. Although no obvious environmental transitions occur in this region, a number of avian species pairs replace each other in western Caribbean Panama, so the region is a suture zone (sensu Remington 1968). However, none of the other contact zones occur in the same exact location as the Manacus contact near population 9 (Olson 1993). The lowland forest habitat of Manacus in western Panama is restricted to a thin coastal strip sandwiched between the mountains and the sea. This ribbon of habitat is especially narrow around populations 8 and 9, perhaps creating a bottleneck for dispersal. Tension zones are expected to move to regions where dispersal into the zone is equivalent for the two parental species, which may explain the location of the clines in this area. The Changuinola River represents another possible region to which the zone would be expected to move, because dispersal appears to be interrupted by this barrier (Brumfield 1999). However, its effect may be less pronounced. Morphometric analysis of historical specimens from near population 5 suggests that those clines have actually moved several kilometers eastward over the past 100 years, away from the Changuinola River (Brumfield unpubl. data).

\section{Divergent Cline Widths}

Assuming the hybrid zone is in equilibrium, additional insights into the architecture of manakin speciation are possible through comparisons of the relative widths of independent clines. Clines for six of the seven molecular loci did not differ in position or width, a pattern that is consistent 
A)

B)
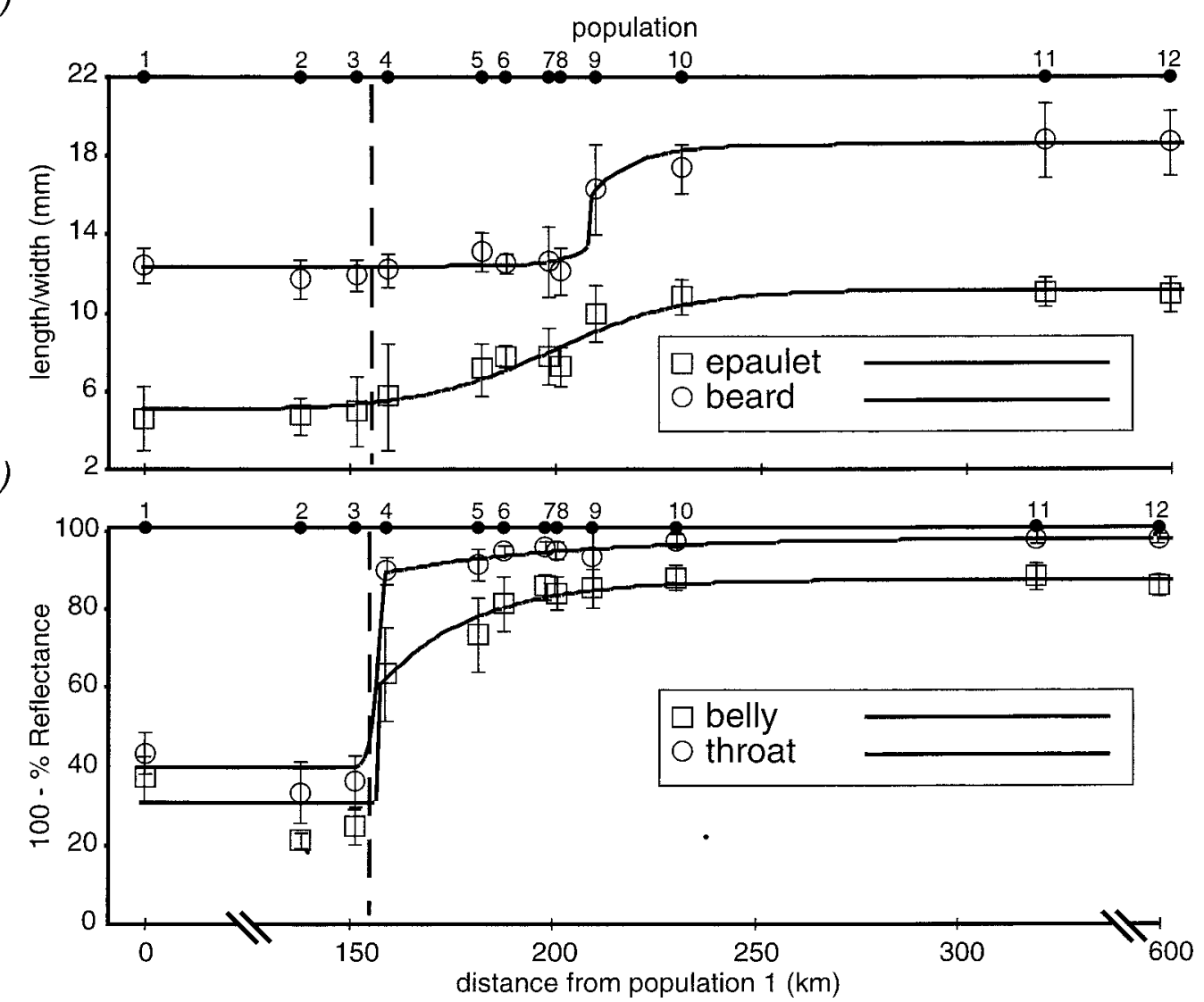

FIG. 5. Fitted clines for (A) beard length and epaulet width and (B) collar color and belly color as measured by percent reflectance at $490 \mathrm{~nm}$ and $665 \mathrm{~nm}$, respectively. Error bars are standard deviations. The vertical dashed line indicates the position of the Changuinola River. Bars on the $x$-axis denote a nonlinear break in geographic distance.

with a tension zone model wherein hybrid zone stability is mediated by a balance between the influx of parentals into the zone and the removal of hybrids due to selection (Haldane 1948; Barton 1983). Both endogenous and exogneous selection would have the same general impact on cline structure if "speciation genes" exist throughout the genome. Concordance of cline widths reflects the sum of effects of loci acting in association over the genome.

The Ada cline was significantly broader than the other molecular clines, although we caution that this conclusion assumes that the hyperbolic tangent function was an adequate

TABLE 7. Maximum-likelihood parameter estimates for morphological character clines. See Table 4 for parameter definitions.

\begin{tabular}{lrrrrr}
\hline \hline & PC1 & $\begin{array}{r}\text { Beard } \\
\text { length }\end{array}$ & $\begin{array}{c}\text { Epaulet } \\
\text { width }\end{array}$ & $\begin{array}{c}\text { Collar } \\
\text { color }\end{array}$ & $\begin{array}{r}\text { Belly } \\
\text { color }\end{array}$ \\
\hline$w$ & 13.9 & 10.3 & 65.2 & 4.4 & 3.0 \\
$w 1$ & 9.7 & 7.2 & 44.8 & 3.0 & 2.1 \\
$c$ & 208.7 & 208.8 & 200.0 & 157.6 & 157.8 \\
$p_{\min }$ & 0.3 & 0.6 & 0.3 & 0.4 & 0.3 \\
$p_{\max }$ & 0.7 & 0.8 & 0.7 & 1.0 & 0.9 \\
$B_{c}$ & 61. & 1.3 & 7500 & 96.4 & 1041.2 \\
$\Theta_{c}$ & 0.0 & 0.8 & 0.9 & 0.4 & 0.2 \\
$B_{v}$ & 1000 & 0.9 & 12.3 & 54.2 & 8.2 \\
$\Theta_{v}$ & 0.8 & 0.2 & 0.1 & 0.0 & 0.0 \\
\hline
\end{tabular}

model of character transition. Ada was also the only locus that was strongly polymorphic in both parental forms. We might expect, a priori, that polymorphic loci are less likely to be subject to incompatibility selection from the simple fact that both alleles exist in both parental populations. Thus, the greater degree of bidirectional introgression at Ada is consistent with the idea that it is experiencing less selection and more introgression than other loci. The same may be true of the epaulet width cline. While selection against hybrids may have limited introgression at some loci, it clearly has not prevented introgression of Ada alleles or of vitellinus color traits.

Although clines for the six concordant molecular loci are on the whole very similar, they differ in their tails of low level introgression. The mtDNA displayed the least amount of introgression; the vitellinus mitochondrial haplotype was not detected west of population 8, unlike other vitellinus markers, which were all found at least as far west as population 2. Less extensive sampling on the east side of the hybrid zone prevents any strong conclusions regarding introgression of the candei haplotype. It is noteworthy that the difference among markers in the extent of low level introgression is readily apparent in allele frequencies (Table 2), but is not conveyed by either cline width measure (Table 4).

The apparently limited introgression of mtDNA in the man- 


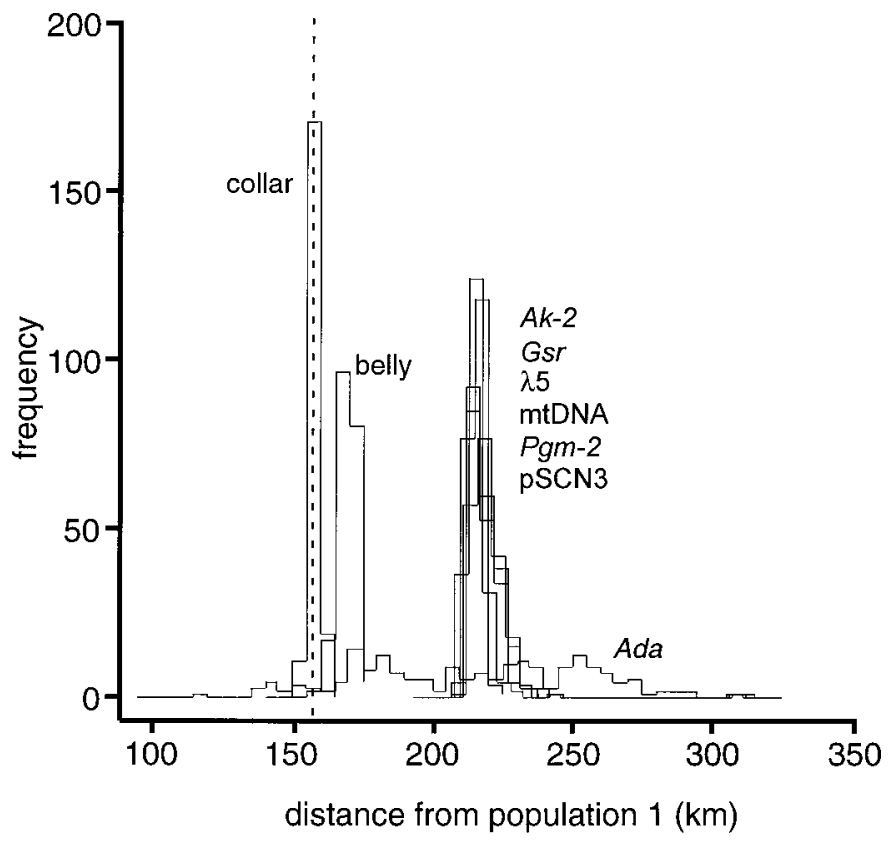

FIG. 6. Histograms showing significant displacement of 200 bootstrap cline centers for introgressing lemon collar color and greenish belly color relative to most of the genetic markers. The position of the Ada cline could not be estimated with confidence. The position of the Changuinola River is indicated by the vertical dashed line.

akin hybrid zone may be a stochastic effect of the smaller effective population size inherent in a uniparental haploid locus. There may also be an effect related to Haldane's rule (Haldane 1922; Coyne and Orr 1989), given that mtDNA is maternally inherited and females are the heterogametic sex in birds. However, there are good reasons to suspect that selection could contribute to this pattern as well. From a purely biochemical perspective, the fact that many essential genetic functions are packed onto the small mtDNA molecule suggests that incompatibilities could arise readily. The lack of recombination in mtDNA precludes the removal of incompatibilities from a haplotype. Finally, because the mitochondrial genome is haploid, all variation is exposed to selection in all individuals. Thus, its limited introgression could be due to the same forces that produce narrow clines at sex chromosome markers (Coyne and Orr 1989; Tucker et al. 1992; Dod et al. 1993).

\section{Marker Choice in Hybrid Zone Studies}

The contrast between the sharp clines for diagnostic markers and the broad, bidirectional introgression observed at the polymorphic locus Ada highlights a bias in hybrid zone studies that may be subtly influencing our views of speciation. Evolutionary biologists typically characterize hybrid zones using diagnostic traits that show fixed differences between parental taxa. The choice seems natural, because hybrids can be identified unambiguously with such markers and any occurrence of a foreign allele can be interpreted as introgression. However, if we are interested in gaining a quantitative sense of introgression across a hybrid zone, diagnostic loci are likely to give an underestimate. Diagnostic loci, on average, are likely to be under stronger selection than other loci for the reasons given above. When they are, diagnostic loci will yield underestimates of average introgression, because relevant modes of selection will oppose the movement of alleles across a hybrid zone (Sattler and Braun 2000).

The strength of this bias will vary with the degree of genomic divergence between hybridizing taxa. When substantial genomic divergence is present, there are likely to be many genetic incompatibilities spread throughout the genome, and many diagnostic markers all experiencing similar levels of generalized selection against hybrids (Foltz 1997), because physical linkage and gametic disequilibria can extend the effects of selection at one locus to others. This is the classic tension zone model, where the sum of the effects of these associated loci creates a genomewide barrier to introgression (Barton and Hewitt 1989). At a finer scale, the strength of this barrier to introgression will vary among regions of the genome depending on the number of loci under selection and the degree of physical or epistatic linkage of marker loci to them (Barton and Bengtsson 1986). By sampling enough markers, molecular data can provide a detailed map of selection intensities experienced across the entire genome (Kim and Rieseberg 1999).

Compared to many organisms, bird species typically show low levels of genetic divergence and low levels of hybrid dysfunction (Avise 1994). Thus, the bias caused by using diagnostic rather than nondiagnostic markers as estimators of average introgression is likely to be large. Indeed, a relative dearth of genetic markers is often available for distinguishing closely related avian species. In studies of hybrid zones, ornithologists have had no choice but to include markers that are not diagnostic, sometimes characterizing hybrid zones without a single diagnostic genetic marker (e.g., Barrowclough 1980). The serendipitous benefit is that these may represent neutral or weakly selected markers (Sattler and Braun 2000), loci that are more likely to reveal nuclear introgression.

By focusing strictly on diagnostic markers, we tend to create a self-fulfilling paradigm of hybrid zones as black holes: Genes go in but they do not come out. This view has led some to suggest that studies of hybridization are irrelevant to speciation (Gill et al. 1993). We encourage hybrid zone researchers to examine the structure of as many genetic markers as possible, including both diagnostic and nondiagnostic loci. Similar cline widths among many unlinked loci (including those likely to be neutral) provide evidence for strong genomewide selection, whereas differences in cline structure reveal distinct forces acting at different loci. Although the likelihood of introgression across hybrid zones will vary with degree of genomic divergence (Barton and Bengtsson 1986; Foltz 1997), in most cases these zones probably provide a evolutionary conduit through which adaptive and neutral traits can move (Piálek and Barton 1997; Barton 2001), enlarging the pool of genetic variation available to both parental populations (Parsons et al. 1993).

\section{ACKNOWLEDGMENTS}

We thank the late C. Handley for setting up fieldwork in Panama; R. Clay, T. Glenn, J. Blake, L. Horth, A. Pineda Sr., A. Pineda Jr., A. Cedeño, and K. Gorrichátegui for field 
assistance; and INRENARE for granting collecting permits in Panama. M. Leone, G. Maggiori, E. Bermingham, and others at the Smithsonian Tropical Research Institute facilitated our work in Panama. T. Glenn, C. Huddleston, G. Sattler, T. Parsons, and others at the Laboratory of Molecular Systematics provided technical assistance. S. J. E. Baird assisted with cline-fitting analyses and provided criticisms of the manuscript. E. Russek-Cohen helped design the likelihood-ratio tests. J. Dean assisted in the preparation and cataloging of specimens. For lending skins, we thank the curatorial staffs of the Louisiana State University Museum of Natural Science (Baton Rouge), the Carnegie Museum of Natural History (Pittsburgh), and the Museum of Vertebrate Zoology (Berkeley). We thank the Louisiana State University Museum of Natural Sciences Collection of Genetic Resources for providing tissues from Costa Rica. M. Baker assisted with reflectance spectrophotometry. D. Cole kindly prepared Figure 1 . H. L. Gibbs and two anonymous reviewers provided constructive comments on the manuscript. This research was supported in part by a Smithsonian Predoctoral Fellowship to RTB.

\section{Literature Cited}

Anderson, E. 1949. Introgressive hybridization. John Wiley, New York.

Anderson, E., and L. Hubricht. 1938. Hybridization in Tradescantia. III. The evidence for introgressive hybridization. Am. J. Bot. 25:396-402.

Arnold, M. L. 1992. Natural hybridization as an evolutionary process. Annu. Rev. Ecol. Syst. 23:237-261.

_ 1997. Natural hybridization and evolution. Oxford Univ. Press, New York.

Avise, J. C. 1994. Molecular markers, natural history, and evolution. Chapman and Hall, New York.

Barrowclough, G. F. 1980. Genetic and phenotypic differentiation in a wood warbler (genus Dendroica) hybrid zone. Auk 97: $655-668$.

Barton, N. H. 1979. Gene flow past a cline. Heredity 43:333-339. 1983. Multilocus clines. Evolution 37:415-426.

1993. Hybrid zones: Why species and subspecies? Curr. Biol. 3:797-799.

- 2001. The role of hybridization in evolution. Mol. Ecol. 10:551-568.

Barton, N. H., and S. J. E. Baird. 1999. Analyse: software for analysis of geographic variation and hybrid zones. Ver. 1.03 for Macintosh. Available via http://helios.bto.ed.ac.uk/evolgen/ Mac/Analyse/index.html.

Barton, N. H., and B. O. Bengtsson. 1986. The barrier to genetic exchange between hybridising populations. Heredity 56: 357-376.

Barton, N. H., and G. M. Hewitt. 1985. Analysis of hybrid zones. Annu. Rev. Ecol. Syst. 16:113-148.

1989. Adaptation, speciation, and hybrid zones. Nature 341:497-503.

Brumfield, R. T. 1999. Evolution of brilliant male plumage traits in Manacus. Ph.D. diss., University of Maryland, College Park, MD.

Brumfield, R. T., and M. J. Braun. 2001. Phylogenetic relationships in bearded manakins (Pipridae: Manacus) indicate that male plumage color is a misleading taxonomic marker. Condor 103: $248-258$.

Buckley, P. A. 1987. Mendelian genes. Pp. 1-44 in F. Cooke and P. A. Buckley, eds. Avian genetics. Academic Press, San Diego, CA.

Butlin, R. K., and R. M. Neems. 1994. Hybrid zones and sexual selection. Science 265:122.

Butlin, R. K., M. G. Ritchie, and G. M. Hewitt. 1991. Comparisons among morphological characters and between localities in the Chorthippus parallelus hybrid zone (Orthoptera: Acrididae). Philos. Trans. R. Soc. Lond. B 334:297-308.

Coyne, J. A., and H. A. Orr. 1989. Two rules of speciation. Pp. 180-207 in D. Otte and J. A. Endler, eds. Speciation and its consequences. Sinauer, Sunderland, MA.

Dod, B., L. S. Jermiin, P. Boursot, V. H. Chapman, J. T. N. Nielsen, and F. Bonhomme. 1993. Counterselection on sex chromosomes in the Mus musculus European hybrid zone. J. Evol. Biol. 6: 529-546.

Dowling, T. E., C. Moritz, J. D. Palmer, and L. H. Rieseberg. 1996. Nucleic acids. III. Analysis of fragments and restriction sites. Pp. 249-320 in D. M. Hillis, C. Moritz, and B. K. Mable, eds. Molecular systematics. Sinauer, Sunderland, MA.

Dumolin-Lapégue, S., A. Kremer, and R. J. Petit. 1999. Are chloroplast and mitochondrial DNA variation species independent in oaks? Evolution 53:1406-1413.

Edwards, A. W. F. 1972. Likelihood. Johns Hopkins Univ. Press, Baltimore, MD

Efron, B., and R. J. Tibshirani. 1993. An introduction to the bootstrap. Chapman and Hall, New York.

Endler, J. A. 1977. Geographic variation, speciation, and clines. Princeton Univ. Press, Princeton, NJ.

1990. On the measurement and classification of colour in studies of animal colour. Biol. J. Linn. Soc. 41:315-352.

Endler, J. A., and M. Théry. 1996. Interacting effects of lek placement, display behavior, ambient light, and color patterns in three Neotropical forest-dwelling birds. Am. Nat. 148:421-452.

Feinberg, A. P., and B. Vogelstein. 1993. A technique for radiolabeling DNA restriction endonuclease fragments to high specific activity. Anal. Biochem. 132:6-13.

Foltz, D. W. 1997. Hybridization frequency is negatively correlated with divergence time of mitochondrial DNA haplotypes in a sea star (Leptasterias spp.) species complex. Evolution 51:283-288.

Gill, F. B., A. M. Mostrom, and A. L. Mack. 1993. Speciation in North American chickadees. I. Patterns of mtDNA divergence. Evolution 47:195-212.

Grant, P. R., and B. R. Grant. 1994. Phenotypic and genetic effects of hybridization in Darwin's finches. Evolution 48:297-316.

Grant, V. 1981. Plant speciation. Columbia Univ. Press, New York.

Haldane, J. B. S. 1922. Sex ratio and unisexual sterility in animal hybrids. J. Genet. 12:101-109.

- 1948. The theory of a cline. J. Genet. 48:277-284

Harris, H., and D. A. Hopkinson. 1976. Handbook of electrophoresis in human genetics. North-Holland Publishing, Amsterdam.

Harrison, R. G. 1990. Hybrid zones: windows on the evolutionary process. Pp. 69-128 in D. Futuyma and J. Antonovics, eds. Oxford surveys in evolutionary biology. Vol. 7. Oxford Univ. Press, Oxford, U.K.

Hastings, W. K. 1970. Monte Carlo sampling methods using Markov chains and their applications. Biometrika 57:97-109.

Hewitt, G. M. 1988. Hybrid zones: natural laboratories for evolutionary studies. Trends Ecol. Evol. 3:158-167.

Hughes, J. M. 1982. An explanation for the asymmetrical 'hybrid zone' between white-backed and black-backed magpies. Emu 82:50-53.

Hunter, R. S. 1975. The measurement of appearance. Wiley and Sons, New York.

Jaarola, M., H. Tegelström, and K. Fredga. 1997. A contact zone with noncoincident clines for sex-specific markers in the field vole (Microtus agrestis). Evolution 51:241-249.

Johnson, N. K., and A. H. Brush. 1972. Analysis of polymorphism in the sooty-capped bush tanager. Syst. Zool. 21:245-262.

Key, K. H. L. 1968. The concept of stasipatric speciation. Syst. Zool. 17:14-22.

Kim, S.-C., and L. H. Rieseberg. 1999. Genetic architecture of species differences in annual sunflowers: implications for adaptive trait introgression. Genetics 153:965-977.

Lewontin, R. C., and L. C. Birch. 1966. Hybridization as a source of new variation for adaptation to new environments. Evolution 20:315-336.

Lill, A. 1974. Sexual behavior of the lek-forming white-bearded 
manakin (Manacus manacus trinitatis Hartert). Z. Tierpsychol. $36: 1-36$

MathSoft. 1999. S-plus 2000. MathSoft, Inc., Seattle, WA.

May, R. M., J. A. Endler, and R. E. McMurtrie. 1975. Gene frequency clines in the presence of selection opposed by gene flow. Am. Nat. 109:659-676.

McDonald, D. B., R. P. Clay, R. T. Brumfield, and M. J. Braun. 2001. Sexual selection on plumage and behavior in an avian hybrid zone: experimental tests of male-male interactions. Evolution 55:1443-1451.

Metropolis, N., A. W. Rosenbluth, M. N. Rosenbluth, A. H. Teller, and E. Teller. 1953. Equations of state calculations by fast computing machines. J. Chem. Phys. 21:1087-1092.

Moore, W. S. 1977. An evaluation of narrow hybrid zones in vertebrates. Q. Rev. Biol. 52:263-277.

Olson, S. L. 1993. Contributions to avian biogeography from the archipelago and lowlands of Bocas del Toro, Panama. Auk 110: 100-108.

Parsons, T. J., S. L. Olson, and M. J. Braun. 1993. Unidirectional spread of secondary sexual plumage traits across an avian hybrid zone. Science 260:1643-1646.

- 1994. Hybrid zones and sexual selection: response to Butlin and Neems. Science 265:122-123.

Piálek, J., and N. H. Barton. 1997. The spread of an advantageous allele across a barrier: the effects of random drift and selection against heterozygotes. Genetics 145:493-504.

Rao, C. R. 1973. Linear statistical inference and its applications. John Wiley and Sons, New York.

Raymond, M., and F. Rousset. 1995. GENEPOP (version 3.1c): population genetics software for exact tests and ecumenicism. J. Hered. 86:248-249.

Remington, C. L. 1968. Suture-zones of hybrid interaction between recently joined biotas. Pp. 321-428 in T. Dobzhansky, M. K. Hecht, and W. C. Steere, eds. Evolutionary biology. AppletonCentury-Crofts, New York.

Rieseberg, L. H., S. J. E. Baird, and A. M. Desrochers. 1998. Patterns of mating in wild sunflower hybrid zones. Evolution 52: 713-726.

Rieseberg, L. H., J. Whitton, and K. Gardner. 1999. Hybrid zones and the genetic architecture of a barrier to gene flow between two sunflower species. Genetics 152:713-727.

Rohwer, S., and C. Wood. 1998. Three hybrid zones between hermit and townsend's warblers in Washington and Oregon. Auk 115: 284-310.
Rohwer, S., E. Bermingham, and C. Wood. 2001. Plumage and mitochondrial DNA haplotype variation across a moving hybrid zone. Evolution 55:405-422.

SAS Institute. 2000. JMP: statistical discovery software. SAS Institute, Inc., Cary, NC.

Sattler, G. D., and M. J. Braun. 2000. Morphometric variation as an indicator of genetic interactions between black-capped and Carolina chickadees at a contact zone in the Appalachian Mountains. Auk 117:427-444.

Schluter, D. 1988. Estimating the form of natural selection on a quantitative trait. Evolution 42:849-861.

Sheppard, P. M., J. R. G. Turner, K. S. Brown, W. W. Benson, and M. C. Singer. 1985. Genetics and the evolution of Mullerian mimicry in Heliconius butterflies. Philos. Trans. R. Soc. Lond. B 308:433-613.

Slatkin, M. 1973. Gene flow and selection in a cline. Genetics 75: 733-756.

Southern, E. M. 1975. Detection of specific sequences among DNA fragments separated by gel electrophoresis. J. Mol. Biol. 98: 503-517.

Spratt, B. G., Q.-Y. Zhang, D. M. Jones, A. Hutchison, J. A. Brannigan, and C. G. Dowson. 1989. Recruitment of a penicillinbinding protein gene from Neisseria flavescens during the emergence of penicillin resistance in Neisseria meningitidis. Proc. Natl. Acad. Sci. USA 86:8988-8992.

Stebbins, G. L. 1959. The role of hybridization in evolution. Proc. Am. Philos. Soc. 103:231-251.

Szymura, J., and N. H. Barton. 1986. Genetic analysis of a hybrid zone between the fire-bellied toads, Bombina bombina and $B$. variegata, near Cracow in southern Poland. Evolution 40: 1141-1159.

1991. The genetic structure of the hybrid zone between the fire-bellied toads Bombina bombina and B. variegata: comparisons between transects and between loci. Evolution 45:237-261.

Tucker, P. K., R. D. Sage, J. Warner, A. C. Wilson, and E. M. Eicher. 1992. Abrupt cline for sex chromosomes in a hybrid zone between two species of mice. Evolution 46:1146-1163.

Wolfram, S. 1996. The Mathematica book. Cambridge Univ. Press, Cambridge, U.K.

Woodruff, D. S. 1989. Genetic anomalies associated with Cerion hybrid zones: the origin and maintenance of new electrophoretic variants called hybrizymes. Biol. J. Linn. Soc. 36:281-294.

Corresponding Editor: H. L. Gibbs

\section{APPENDix}

Specimen information for each locality. Asterisks denotes reference specimens (populations 1 and 12) for morphological and/or genetic measurements. The $\mathrm{m}$ superscript denotes a definitively plumaged male skin for which all measurements were taken. The mf superscript denotes a definitively plumaged male that was prepared as a flat skin. Only a subset of the morphological measurements were taken on these. Most notably, wing length was not measured. Specimens excluded from the principal components analysis are denoted by the $\mathrm{x}$ superscript. The $\mathrm{s}$ superscript denotes an individual for which only a skeleton preparation is available. These individuals were only assayed for the genetic markers. The $\mathrm{f}$ superscript denotes a female bird, and the g superscript denotes a green, first-year male. The b superscript indicates a banded bird, for which only the restriction-fragment-length-polymorphism markers were assayed. When numbers prefaced with a B appear in brackets, these correspond to tissue catalog numbers, and indicate that the sample was used in genetic analyses. Specimens only having a B number represent blood samples from banded birds. All of the reference specimens are definitively plumaged male birds prepared as skins. The mna superscript indicates definitely plumaged males whose skins were not available for morphological analysis.

Population $\overline{1}$

2

$9^{\circ} 27^{\prime} \mathrm{N} 82^{\circ} 40^{\prime} \mathrm{W}$
Specific locality and specimen catalog numbers

Costa Rica: prov. Limon; $11 \mathrm{~km}$ by road W Guapiles (LSUMNS 138736f [B16157, collected by S. J. Hackett], 138738f [B16278, collected by J. P. O’Neill], B16282 (collected by SJH), 138739* [B16287, collected by SJH], 138740* [B16297, collected by SJH], 138741* [B16298, collected by JPO]); Costa Rica: prov. Limon; 15 km NNE Turrialba (LSUMNS 30623*); Costa Rica: prov. Limon; Guapiles (CM 13210*, 13345*, , 13381*, 13472*); Costa Rica: prov. Limon; Guacimo (CM13517*, 23552*, LSUMNS 35404*); Costa Rica: prov. Limon; Jimenez, old line RR (CM25286*, 155471*, -2*); Costa Rica: prov. Cartago; <1.6 km NE Chitaria (LSUMNS 32524*); Costa Rica: prov. Heredia; Puerto Viejo (MVZ 155647*); Carrillo (CM25453*, 25990*); El Hogar (CM 26758*, -59*, -60*, 26801*, -2*x, 28026*, -7*); Juan Miras (CM 11102*).

Panama: prov. Bocas del Toro; hills on S bank of Rio Sixaola, $25 \mathrm{~km} \mathrm{~W}$ Guabito, (USNM 608191'm [B1879], 608192 ${ }^{\mathrm{m}}$ [B1877], 608193 $3^{\mathrm{ma}, \mathrm{x}}$ [B1878]); Panama: prov. Bocas del Toro, 8 km SW Guabito (USNM 608988 ${ }^{\mathrm{m}, \mathrm{x}}$ [B4590], 608989 [B4595], 608991 ${ }^{\mathrm{f}}$ [B3246], 62013f [B3248], B4554, -5, B4557-61, B4567, B4573-77, B4579, B4582). 
APPENDIX

Continued.

\begin{tabular}{|c|c|}
\hline Population & Specific locality and specimen catalog numbers \\
\hline $\begin{array}{l}3 \\
9^{\circ} 22^{\prime} \mathrm{N} 82^{\circ} 34^{\prime} 50^{\prime \prime} \mathrm{W}\end{array}$ & 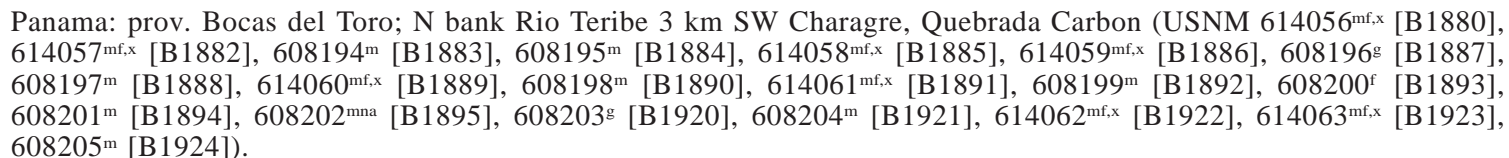 \\
\hline $\begin{array}{l}4 \\
9^{\circ} 24^{\prime} \mathrm{N} 82^{\circ} 31^{\prime} \mathrm{W}\end{array}$ & 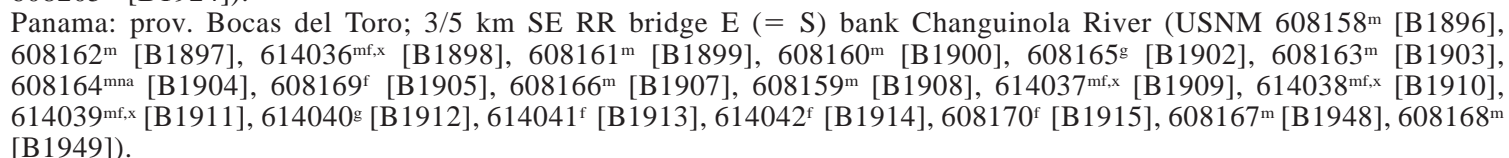 \\
\hline $\begin{array}{l}5 \\
9^{\circ} 15^{\prime} \mathrm{N} 82^{\circ} 25^{\prime} \mathrm{W}\end{array}$ & 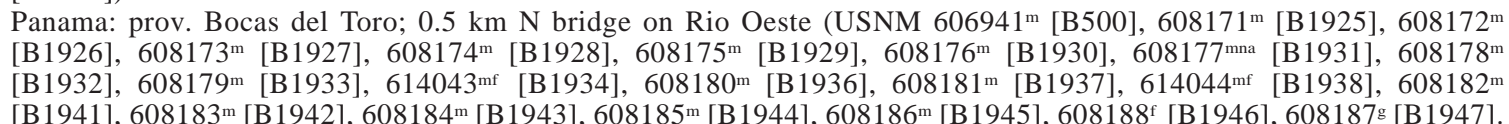 \\
\hline $\begin{array}{l}6 \\
9^{\circ} 12^{\prime} \mathrm{N} 82^{\circ} 22^{\prime} \mathrm{W}\end{array}$ & $\begin{array}{l}\text { Panama: prov. Bocas del Toro; Quebrada Pastores (USNM 606937m }[\mathrm{B} 484], 606939^{\mathrm{m}}[\mathrm{B} 485], 606940^{\mathrm{m}}[\mathrm{B} 486], 606936^{\mathrm{m}} \\
\text { [B488], 606938 }{ }^{\mathrm{m}} \text { ). }\end{array}$ \\
\hline $9^{\circ} 10^{\prime} \mathrm{N} 82^{\circ} 15^{\prime} \mathrm{W}$ & 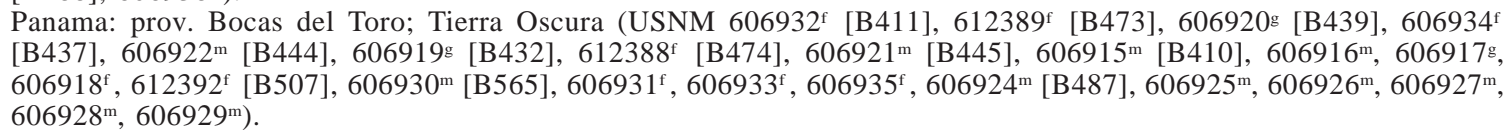 \\
\hline $9^{\circ} 02^{\prime} \mathrm{N} 82^{\circ} 17^{\prime} \mathrm{W}$ & 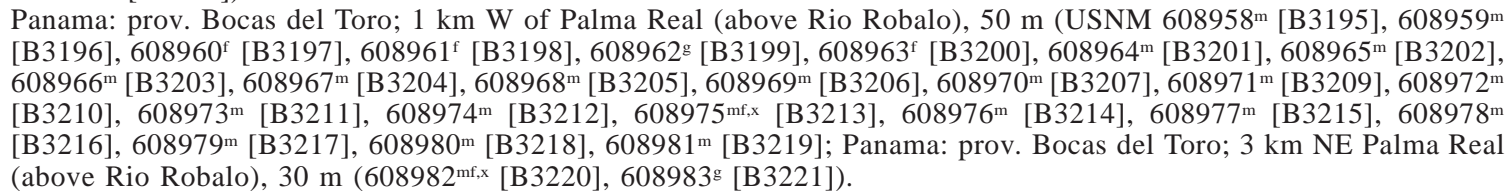 \\
\hline $\begin{array}{l}10 \\
8^{\circ} 55^{\prime} \mathrm{N} 82^{\circ} 08^{\prime} \mathrm{W}\end{array}$ & 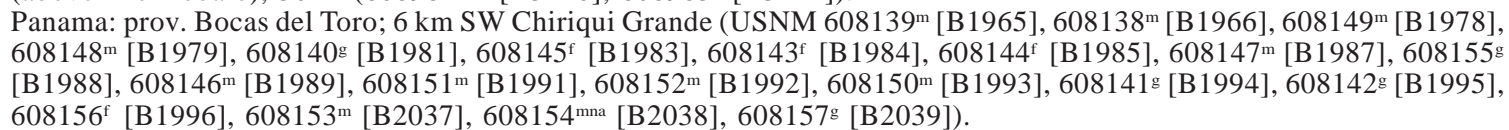 \\
\hline
\end{tabular}

